NASA Technical Memorandum 87/46

AIAA-86-0044

\title{
Wind Tunnel Turning Vanes of Modern Design
}

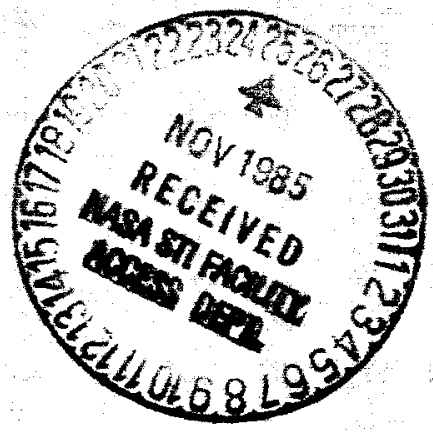

B86-12239

Unclas

63/09 04843

T.F. Gelder, R.D. Moore, J.M. Sanz, and E.R. McFarland

Lewis Research Center

Cleveland, Ohio

Prepared for the

Twenty-fourth Aerospace Sciences Meeting sponsored by the American Institute of Aeronautics and Astronautics Reno, Nevada, January 6-8, 1986 


\section{ERRATA}

NASA Technical Memorandum 87416

AIAA-86-0044

\section{WIND TUNNEL TURNING VANES OF MODERN DESIGN}

T.F. Gelder, R.D. Moore, J.M. Sanz, and E.R. McFarland

The Technical Memorandum number (mentioned on the cover and Report Documentation Page) should be 87146. 
WIND TUNNEL TURNING VANES OF MODERN DESIGN

T.F. Gelder, R.D. Moore, J.M. Sanz, and E.R. McFarland

National Aeronautics and Space Administration

Lewis Research Center

Cleveland, Ohio 44135

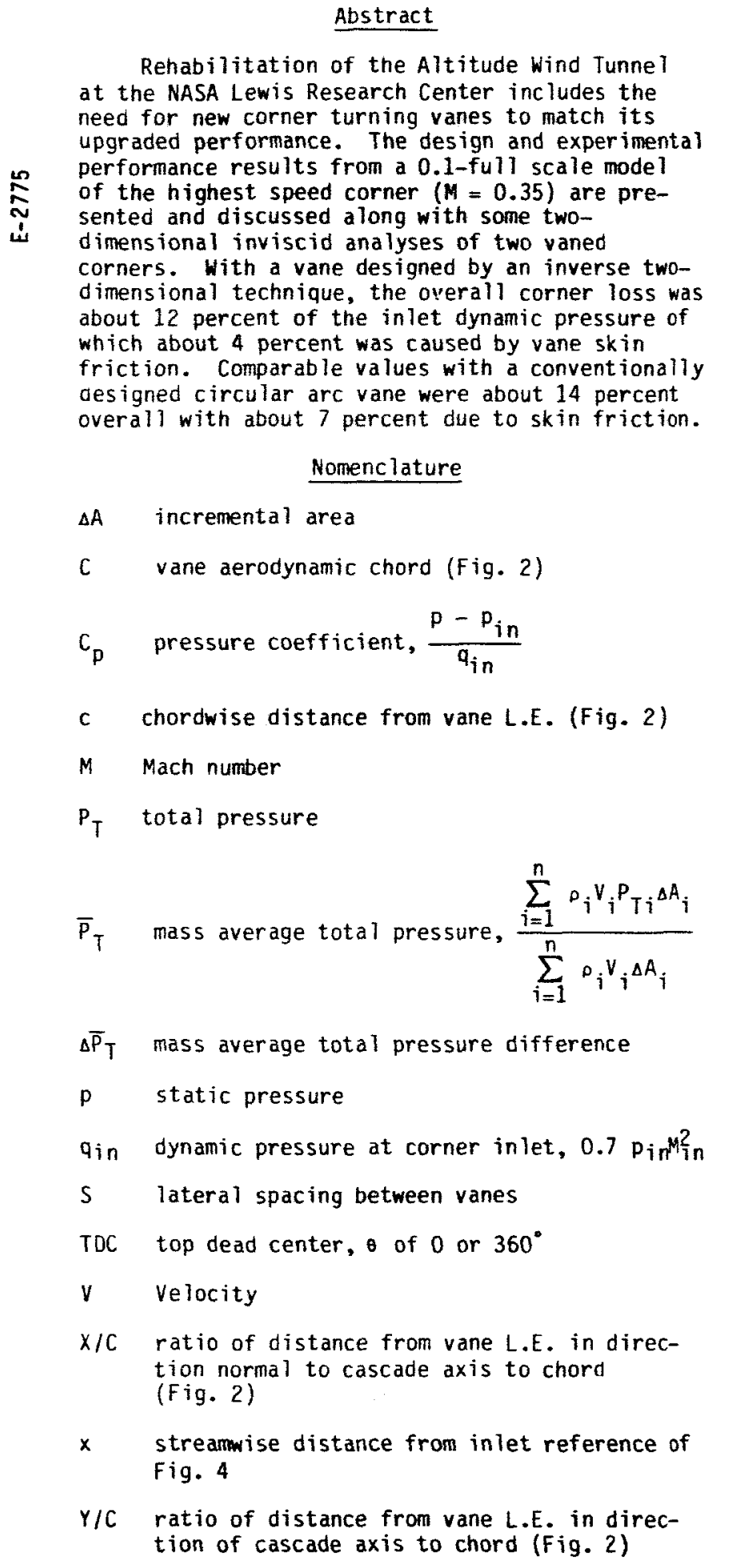

Abstract

at the NASA Lewis Research Center includes the need for new corner turning vanes to match its upgraded performance. The design and experimental performance results from a $0.1-$ full scale model sented and discussed along with some two-

dimensional inviscid analyses of two vaned about 12 percent of the inlet dynamic pressure of which about 4 percent was caused by vane skin friction. Comparable values with a conventionally designed circular arc vane were about 14 percent
overall with about 7 percent due to skin friction.

\section{Nomenclature}

incremental area

vane aerodynamic chord (Fig. 2 )

$c_{p}$ pressure coefficient, $\frac{p-p_{i n}}{q_{i n}}$

chordwise distance from vane L.E. (Fig. 2)

Mach number

$\sum_{i=1}^{n} \rho_{i} V_{i} \Delta A_{i}$

mass average total pressure difference

$S$ lateral spacing between vanes

top dead center, $\theta$ of 0 or $360^{\circ}$

tion normal to cascade axis to chord

streamwise distance from inlet reference of ratio of distance from vane L.E. in direction of cascade axis to chord (Fig. 2) y streamwise distance from out let reference of Fig. 4

B air angle relative to a normal to cascade axis, degrees (Fig. 2)

p density

- circumferential position from TDC looking downstream, degrees

- cascade solidity, C/S

$\bar{\omega} \quad$ vane profile loss coefficient, $\frac{{ }^{\Delta \bar{P}_{T}}}{\mathrm{q}_{T_{\mathrm{n}}}}$

Subscripts

c corner

in inlet, station 11 (Fig. 4)

out outlet, station 34 (Fig. 4)

$\checkmark$ vane

w wall

\section{Introduction}

Rehabilitation of the Altitude Wind Tunnel (AWT) at the Lewis Research Center includes the need for new turning vanes to match its upgraded performance. A plan view of the tunnel and its capabilities are presented in Fig. 1 with further details to be found in Refs. 1 to 3. Vanes have been designed for testing with 0.1 -scale models of all four corners. The design and experimental performance results of this effort for the highest speed corner, number 1, are the subject of the present paper. Because of their more general interest, only the results without the exhaust removal scoop simulated (Fig. 1) are presented here. A companion report ${ }^{4}$ presents tabulated data from all the fixed instrumentation for various corner number 1 configurations including those with the exhaust removal scoop. For the present configuration the design inlet Mach number is 0.35 . The inlet and outlet sections of the corner are circular and of equal diameter $(82.3 \mathrm{~cm}$ at 0.1 full-scale).

Large wind tunnels are usually designed with low Mach numbers around 0.1 entering the corners to minimize the losses in total pressure incurred in turning the flow. These losses are proportional to the inlet velocity squared and have a direct impact on tunnel drive power requirements. One of the design constraints for the upgraded AWT was to utilize the original tunnel shell. But this constraint coupled with the requirement for nigher test section Mach numbers resulted in a significant increase in the Mach number to corner 
number 1 . To satisfy these severe design requirements, a modern vane design was sought to minimize the losses.

Most of the available ijterature on wind tunnel turning vane designs is from 25 to $50 \mathrm{yr}$ old.5-11 The in let Mach numbers studied then were much less than 0.35 , being compatible with the more conventional wind tunnel corner designs. Also, many of these earlier studies were not conducted or reported in sufficient detail to fully evaluate the results. Thus, analytical and experimental studies were conducted to provide we 11 documented design and performance information on wind tunnel turning vanes over a range of inlet Mach numbers from about 0.16 to 0.40 for use in a rehabilitated AWT as well as for a modern data base for more general application.

\section{Design and Analysis Codes}

Recent experience with some turning vanes of modern design for the NASA Ames Research Center's 40 by $80 / 80$ by $120-f t$ wind tunnel has demonstrated performance improvements over older designs. 12,13 Two recently available two-dimensional codes were utilized for the Ames' designs and for the present AWT corner vane designs. One is an inverse design technique by Sanz 14,15 which generates vanes of unique cross section tailored to avoid boundary layer separation from either surface. It includes a boundary layer calculation to judge the nearness of separation and account for displacement thickness. The other is an inviscid analysis code by McF arland.16,17 It uses an improved panel method for solving the governing equations. Vane cross sections with this latter technique were more conventional. They consisted of circular arc surfaces, a circular leading edge segment, and a sharp trailing edge. Emphasis in this paper will be on the Sanz design, hereinafter called vane $A$ or the A vanes. Some comparisons will be made with McFarland's conventional shape, hereinafter called vane $B$ or the $B$ vanes.

The cross section and surface pressure distribution of vane $A$ at design are shown in Fig. 2. It is a relatively thick blade with maximum thickness to chord ratio of 0.196 . The vane solidity or chord-to-spacing ratio is 1.89 , and there is little camber over the aft 1/3-chord. Also indicated is a trunnion (located at each end of the vane span) about which the entire vane could be rotated and locked to a different setting angle to alter the local flow field if desired.

Comparable design information for vane $B$ is shown in Fig. 3. Each vane $B$ is 20 percent thinner than vane $A$, but the cascade solidity is 20 percent higher (four more vanes required) than the vane A configuration.

\section{Test facility and Instrumentation}

The 0.1-scale test facility is shown by a schematic drawing in Fig. $4(\mathrm{a})$ and by a photograph in Fig. 5. As indicated on Fig. 4(a), room air is drawn through a bellmouth, a honeycomb, the corner vanes, and a choked nozzle plate by remote exhausters. Different diameter choke plates were used to vary the corner inlet Mach number at station 11 from about 0.16 to 0.40 .
Some of the instrumentation locations are also indicated on Fig. 4(a). Total pressure surveys were made at stations 11 (inlet) and 34 (outlet). There were fixed total pressure rakes, including boundary layer rakes, every $45^{\circ}$ at both stations, plus radial traverses to 46 percent radius from the wall with a combination probe every $22.5^{\circ}$ at station 34 . The fixed rakes and traverse probes are shown in Fig. 6. Details of the air aligning combination probe (measures total pressure, total temperature, and flow angle, Fig. 6(c)) may be found in Ref. 18.

Locations of tunnel wall static taps are tabulated on Fig. 4(b). In addition there were vane surface pressure taps outlining the flow channels at the four locations, A to D, indicated in the front view of the cascade (Fig. 4(a)).

Vane wake surveys, one-half chord behind the cascade were made at the three locations indicated on Fig. 4(a). The combination probe described above was used at several immersions from the wall and across two vane gaps at each of the three locations. The wake traverse equipment was supported in a plate installed downstream of the vanes, as shown in Fig. 7.

The turning vanes of constant cross section were fabricated to the same span length. These were mounted in a rectangular frame or vane holder as illustrated in Fig. 8 . The end walls were made of flexible foam, the exposed surface of which was carefully trimmed to form the required elliptical contour shown in Fig. 8. The flexible foam provided a continuous end wall surface between the vane leading and trailing edges and made it easy to change vane setting angles.

To visualize the character of the flow, wool tufts were taped onto the transparent tunnel walls and on some of the vane surfaces.

\section{Results and Discussion}

The A vanes were tested at several different combinations of setting angles in an attempt to optimize the overall performance of the corner. The best configuration studied was with all vanes in the cascade rotated $5^{\circ}$ counter-clockwise (from top) from the design setting angle shown on

Fig. 2. This will hereinafter be referred to as the design $-5^{\circ}$ setting angle or $-5^{\circ}$ reset. The following discussion and figures expand on the performance of the $A$ vanes at an in let Mach number of 0.35 in two configurations: one with all vanes at design $-5^{\circ}$ setting angle, and the other with all vanes at the design setting angle.

Character of Flow. The static pressure distributions along the outside corner walls at $\theta$ of $270^{\circ}$ for the two vane setting angles are shown in Fig. 9. The pressure coefficient $C_{p w}$, along the corner inlet section is plotted above and parallel to the inlet wall in part (a). The outlet section $C_{p w}$ 's are plotted to the side of and parallel to the outlet wall in part (b). With $-5^{\circ}$ reset of the vanes, there was a slight deceleration of the outside wall flow approaching the cascade (as evident by increasing values of $C_{\text {pw }}$ ) and a slight acceleration along the outside wal? in leaving the cascade. With $-5^{\circ}$ reset, the wall tufts showed no indication of flow separation or reversal. Also, the measured outlet air angles 
from the vane wake surveys at three locations across the cascade (Fig. $(a)$ ) were within about 1 of the design intent, i.e., parallel to the tunnel walls.

In contrast, at the design setting of the vanes, there was an acceleration of the outside wall flow approaching the cascade which culminated in a strong adverse pressure gradient on the outside wall at the vane outlet (fig. $9(b)$ ). It was in this rapid deceleration region where the tufts started to indicate flow separation from the outside wall and a high degree of flow turbulence. Also, at the design setting angle of the vanes, the flow angle measurements indicated a generai overturning of the flow of about $5^{\circ}$.

Although not shown here, along the inside corner walls ( $\theta$ of $90^{\circ}$ ), there was little change in static pressure approaching or leaving the cascade for either setting angle and no indication of flow separation downstream of the vanes.

Further evidence of the character of the flow is shown by contour plots of total pressure at the corner inlet and out let stations in Figs. 10 and 11, respectively. In Fig. 10 the pressure pattern is symetrical, as expected, with a wall boundary layer about 10 percent radius thick. In Fig. 11 , the contour plots of total pressure reveal a good balance around the circumference for the design $-5^{\circ}$ setting angle (part (a)) with a large central region at relatively high pressure. The wall boundary layer appears to be about 25 percent radius thick. On the other hand at the design setting angle (part (b)), there is a distorted pattern of total pressure. Most of the outside wall, $210^{\circ}<\theta<330^{\circ}$, (approximate ly) shows a steep pressure gradient extending from the wall to about 50 percent radius. Hall tufts that were mounted between the vane trailing edge and outlet station 34 over about this same $\theta$ range indicated separation from the wall and turbulent activity similar to that observed at $\theta$ of $270^{\circ}$. It appears that the acute corners formed by the intersection of the suction surface of the $v$ anes and the wall for $210^{\circ}<\theta<330^{\circ}$ (approximately) contain critical flow regions. The increased vane loading at the design setting angle compared to the design $-5^{\circ}$ setting resulted in a breakdown of the flow in these endwall regions and thus increased losses in total pressure.

Sone representative turbulence intensities were measured with a single sensor hot wire. At the half-radius position at the corner inlet station the intensity varied from 1.0 to 1.3 percent. At the corner outlet station with the vanes at design $-5^{\circ}$, the turbulence intensity at the half radius position was about 3.0 percent while within the wall boundary layer at one-tenth radius, the intensity was about 8 percent.

Code Analyses of Flow. Several analyses of the flow in the corner were made with McFarland's analys is codel6,17 applied to the $A$ vane shape at different combinations of setting angles. Although the code models only two-dimensional, inviscid flow, it can include the effects of the walls of the corner as well as the vanes. The simulated corner is illustrated in Fig. 12(b) which represents the horizontal plane containing the corner centerline. Only 14 of the actual 20 vanes could be simulated along with the walls because of computer memory limitations, but this will be shown to be inconsequential. The spacings between vanes and to either wall were accurately simulated. The inlet Mach number and air angle were also properly modelled by scaling down the total flow in the approach section to match the smaller vane number in the cascade.

Some of the results of these analyses are presented in Figs. 13 and 14. Selected flow vectors (with some Mach number levels indicated for reference lengths) near the inner ( $\theta$ of $90^{\circ}$ ) and outer $\left(\theta\right.$ of $\left.270^{\circ}\right)$ walls of the corner are shown in Fig. 13. At the design $-5^{\circ}$ setting (Fig. 13(a)), the approaching flow Mach numbers to the outer and inner flow channels are nearly the same at about 0.35 . Also, the peak off-body Mach number of about 0.6 is in the outermost channel and diffusing this to the vane out let level was accomplished without any flow separations along the outer wall. Flow through the innermost channel is slowed to a Mach number of about 0.13 near mid-chord, but this effect does not persist in the next or subsequent channels away from the inner wall.

In contrast at the design setting angle (Fig. 13(b)), the flow approaches the outer vanes at a Mach number of about 0.45 while approaching the inner ones at a Mach number of about 0.30 . In the outermost passage between the vane and the wall, the flow accelerates to slightly supersonic levels of 1.015 near vane mid-chord. Diffusing these near sonic Mach numbers to an out let value near 0.4 could not be accomplished without the experimentally observed flow separation on the outer wall. Flow through the innermost channel is slowed to a Mach number near 0.07 near midchord, but as before this effect does not occur in the next or other channels away from the inner wall.

Carpet plots of the Mach numbers on the vane surfaces are shown in Fig. 14. For the design $-5^{\circ}$ setting angle ( $\mathrm{Fig.} \mathrm{14(a)),} \mathrm{the} \mathrm{maximum} \mathrm{upper}$ surface Mach number on the outermost vane was only about 0.7 . Diffusing this to the trailing edge level of about 0.3 was accomplished without any visible separation of the flow on this surface. At the design setting angle (Fig. 14(b)), Mach numbers as high as 1.2 occur on the upper surface of the outermost vane. Flow on this surface was experimentally observed to separate before the trailing edge. Only a vane or two away from either wall, at either setting angle, the vane surface Mach number distributions become nearly the same for all other interior vanes.

It is also interesting to note that resetting or respacing only the first vane or two nearest either wall did not alter the character of the overall flow significantly. This was demonstrated in analytical studies like the ones just described and in the experiments with the actual hardware where such configurations were tried. 4

These two-dimensional, inviscid analyses appear to give a useful indication of what the real flow is doing in the cascade, including that in the outermost and innermost flow channels in the horizontal plane containing the centerline at least. Perhaps visualizing similar flow patterns for other horizontal planes above and below the 
centerline is helpful in understanding the flow breakdown in the outermost channels for other $\theta$ values, from $210^{\circ}$ to $330^{\circ}$ for example, with the vanes at the design setting angle. Such analyses should be useful in directing possible improvements to overall corner designs.

Vane surface pressure. Experimental values of vane A surface pressure distributions at four locations and two setting angles are presented in Fig. 15. At the design $-5^{\circ}$ setting ( $\mathrm{Fig}$. 15(a)), the surface pressure distributions are about the same at locations $A$ to $C$. For all locations, the upper surface $C_{p v}$ distributions show no significant flattening out before the trailing edge which is often indicative of flow separation. There is a modest adverse pressure gradient near the leading edge on the pressure surface for locations $A$ to $C$ which is caused by the vane reset of $-5^{\circ}$. However, as will be shown, this did not adversely effect the vane two-dimensional losses for this configuration.

At the design setting (Fig. 15(b)), and for the central locations, $B$ and $C$, the measured surface pressures are close to the indicated twodimensional design values (Sanz, Refs. 14 and 15). This is not true at locations $A$ and $D$. Distributions at $A$ and $D$ reflect the unbalanced approach flow (see Fig. 13(b)) and other unknown threedimensional effects. At the outboard A location (Fig. 15(b)), there is no evidence from the pressure distribution of flow separation from the upper surface on this second vane from the outer wall (see also Fig. 14(b)).

Vane wake surveys. Results from some typical $v$ ane wake surveys behind the central pair of vanes and at three spanwise locations are shown in Fig. 16. These data are from the most nearly twodimensional part of the flow. The total pressures are presented in coefficient form, thus its average across a vane gap equals the profile loss coefficient, $\bar{\omega}$, shown. The average loss coefficient (based on mass averaged total pressures) in the two-dimensional regime is about 0.04 , irrespective of setting angle, with a data scatter of about +0.005 . This is the vane profile loss component of the total corner loss and is primarily the result of skin friction. This skin friction loss level is in close agreement with a boundary layer loss calculation 19 if transition is assumed near the leading edge on both surfaces.

There was a significant effect of vane setting angle on the outlet air angles also shown on Fig. 16. At the design setting angle (Fig. 16(b)), the flow in the free stream part of the wake survey was overturned about $5^{\circ}$ since the angle measured was about $-50^{\circ}$ rather than $-45^{\circ}$ (referenced to a normal to the cascade axis). This may have been caused in part by the flow separation on the outer wall along with other three-dimensional, viscous effects not addressed with the design code. By resetting the vanes $-5^{\circ}$, the outlet air angle was measured at about $-44^{\circ}$ (Fig. 16(a)), or within about $1^{\circ}$ of the desired value.

Overall corner losses. The corner 1 losses over a range of inlet Mach numbers are summarized on Fig. 17. The A vanes (Fig. 2) at two setting angles (design and design $-5^{\circ}$ ) are shown and compared to the more conventional circular arc $B$ vanes (Fig. 3) tested at their design setting in the same corner and facility.

From Fig. 17, the overall corner loss coefficient for the $A$ vanes at the design inlet Mach number of 0.35 was about 0.12 for the design $-5^{\circ}$ setting angle and about 0.16 for the design setting. Compared to the design setting, the reset $-5^{\circ}$ configuration provided a much better balance of the flow approaching the cascade. This avoided a breakdown of the flow in the vane end-outer wall intersection regions around the outside of the corner, $210^{\circ}<\theta<330^{\circ}$, approximately. The net result was this 25 percent decrease in loss. The $-5^{\circ}$ reset also provided the desired corner out let air angle. With the $B$ vanes at design setting angle, the loss coefficient was about 0.14 . Here the outer wall tutfs indicated the flow remained attached in the vane outlet region and the outlet air angle was within about $1^{\circ}$ of that desired. Thus there was no reason to reset the $B$ vanes. The corner loss difference between using the $A$ vanes reset $-5^{\circ}$ and the $B$ vanes at design is due mainly to the lower vane skin friction component with the $A$ vanes. For the $A$ vanes the skin friction loss was about 0.04 (Fig. 16); for the $B$ vanes it was about 0.07 (not shown in this paper).

The $A$ vane tolerance to possible inlet flow angle distortion should also be better than for the $B$ vane design, at least in the two-dimensional regions of the flow. This is because there is no upper surface pressure spike near the leading edge for the $A$ vane (Fig. 15(a)) like there is for the $B$ vane (Fig. 3). Such spikes could be sufficiently increased by higher than design inlet flow angles to cause premature separation from the vane surface and thus higher loss and an off design outlet air angle.

The corner loss coefficients (Fig. 17) decreased slightly with decreasing in let Mach number. Although not shown, vane $B$ data indicated the two-dimensional vane skin friction component of the corner loss coefficient did not vary with in let Mach number. Thus, the decrease in corner loss is attributed to decreased losses in the vane end wall regions and to reduced eddy activity from turning a three-dimensional flow around a corner. These three-dimensional losses comprise about two-thirds of the total corner coefficient for the $A$ vanes reset $-5^{\circ}$ and are believed to be independent of Reynolds number. Such an assumption was made by Wattendorf. 20

The loss coefficients of Fig. 17 are based on mass-averaged total pressure. Locally measured static and total pressures from all rakes and combination probes were used when available. However, the use of an average static pressure from the wall taps and total pressures from the fixed diametrical rakes resulted in nearly the same overall, mass-averaged, loss coefficients (see open versus solid symbols on Fig. 17).

Comparisons with literature. Only two references were found where overall corner loss coefficients for $90^{\circ}$ turning vanes in a constant diameter circular duct were given. These were for relatively low inlet Mach numbers of about 0.1 . Krober 5 reports a loss coefficient of 0.135 . Results from a Russian handbook of hydraulic resistance which is translated into English in Ref. 10 , indicates a range of values from 0.26 to 
0.33. This variation depended on vane number and lateral spacing and was for corners that were cut off the length of the vane chord just like the present configurations (see Fig. 9). The minimum loss coefficient shown in Ref. 10 was 0.18 where these corner cut-offs were rounded. At an inlet Mach number of 0.1 , the present data indicate loss coefficients of about 0.10 for the $A$ vanes reset $-5^{\circ}$ and about 0.12 for the $B$ vanes.

Some recent, two-dimensignal results from the NASA Ames Research Center 3 give an areaaveraged loss coefficient from vane wake survey measurements for a McFarland designed circular arc vane similar to the $B$ vane in the present paper. This loss coefficient obtained in a rectangular flow channel does not include the very near wall data at the ends or sides of the channel. Thus, the reported loss level of 0.07 for an inlet Mach number near 0.1 is lower than the overall corner value in a circular duct of about 0.12 for the $B$ vanes on Fig. 17. However, from wake surveys done in the two-dimensional flow region behind the central pair of $B$ vanes in the present study (but not shown here) the loss coefficient was about 0.07 , the same as the Ames result.

In another Ames study, 21 a two-dimensional corner with conventional circular arc vanes (like the $B$ vanes) was tested. There, corner loss coefficients from about 0.11 to 0.13 are reported for inlet Mach numbers near 0.1. These Ames' total pressure loss coefficients were determined from wall static pressures across the corner using the incompressible Bernoulli equation and the continuity equation. These coefficients include the viscous end and side wall effects. A similar calculation with the $B$ vane data from the present study gave about these same values which in turn agree with the mass-averaged total pressure loss coefficients on Fig. 17. However, this apparent agreement between loss coefficients using total pressure differences from either wall static pressure derived values or directly measured mass-averaged values may be fortuitous. This is because the static pressures across either inlet or outlet stations were not constant with radius for the present configurations tested. Apparentiy these variations tended to cancel out in determining a pressure differences across the corners studied.

\section{Summary of Results}

Turning vanes for use in the highest speed corner, with circular ducting, of an upgraded Altitude Wind Tunnel (AWT) at the NASA Lewis Research Center have been designed with modern techniques and tested in a 0.1 full-scale facility with the following principal results.

1. At the design corner inlet Mach number of 0.35 , the overall corner loss was only about 12 percent of the inlet dynamic pressure with turning vanes designed by an inverse twodimensional technique, of which about 4 percent was caused by the vane skin friction. Comparable values for recently designed, but conventionally shaped circular arc type vanes tested in the same facility were about 14 percent overall with about 7 percent due to skin friction. For both, the corner outlet air angles were within about $1^{\circ}$ of the design intent.
2. Use of flow solutions from a twodimensional, inviscid analys is code to indicate what the real flow may be doing at least in the horizontal plane containing the corner centerline was demonstrated. Such a code should be useful in directing possible improvements to overall corner designs.

\section{References}

1. Chamberlin, R., "The Altitude Wind Tunnel (AWT) - A Unique Facility for Propulsion System and Adverse Weather Testing," AIAA Paper 85-0314, Jan. 1985.

2. Abbott, J.M., Diedrich, J.H., Groeneweg, J.F., Povineili, L.A., Reid, L., Reinnann, J.J. and Szuch, J.R., "Analytical and Physical Modeling Program for the NASA Lewis Research Center's Altitude Wind Tunnel (AWT)," AIAA Paper 85-0379, Jan. 1985.

3. Blaha, B.J. and Shaw, R.J., "The NASA Altitude Wind Tunnel: Its Role in Advanced Icing Research and Development," AIAA Paper 85-0090, Jan. 1985.

4. Moore, R.D., Boldman, D.R. and Shyne, R.J., "Experimental Evaluation of Two Turning Vane Designs for Corner 1 of 0.1-Scaled Model of NASA Lewis Research Center's Altitude Wind Tunnel," Proposed NASA TP.

5. Krober, 6., "Guide Vanes for Deflecting Fluid Currents with Small Loss of Energy," NACA TM-722, 1933. (Ingenieur-Archiv, Vol. 3. 1932).

6. Patterson, G.N., "Note on the Design of Corners in Duct Systems," ARC R\&M-1773, 1936.

7. Collar, A.R., "Some Experiments with Cascades of Aerofoils," ARC R\&M-1768, 1936.

8. Salter, C., "Experiments on Thin Turning Vanes," ARC R\&M-2469, 1946.

9. Winter, K.G., "Comparative Tests of Thick and Thin Turning Vanes in the Royal Aircraft Establishment $4 \times 3-\mathrm{Ft}$. Wind Tunnel," ARC R\&M-2589, 1947.

10. Idel'chik, I.E., Handbook of Hydraulic Resistance. Coefficients of Local Resistance and of Friction, AEC-TR-6630, 1966.

11. Pope, A and Harper, J.J., Low-Speed Wind Tunnel Testing, John Wiley and Sons, New York, 1966.

12. Sanz, J.M., McFarland, E.R., Sanger, N.L., Gelder, T.F., and Cavicchi, R.H., "Design and Performance of a Fixed, Nonaccelerating Guide Vane Cascade that Operates Over an Inlet Flow Angle Range of 60 Degrees," Journal of Engineering for Gas Turbines and Power, Vol. 107, No. 2, Apr. 1985, pp. 477-484.

13. Corsiglia, V.R., 01son, L.E., and Falarski, M.D., "Aerodynamic Characteristics of the 40-by 80/80-by 120-Foot Wind Tunnel at NASA Ames Research Center, " NASA TM-85946, 1984. 
14. Sanz, J.M., "Design of Supercritical Cascades with High Solidity," AIAA Journal, Vol. 2l, No. 9, Sept. 1983, pp. 1289-1293.

15. Sanz, J.M., "Improved Design of Subcritical and Supercritical Cascades Using Complex Characteristics and Boundary Layer Correction," Universities Space Research Association, Columbia, MD, May 1983. (NASA CR-168166).

16. McFarland, E.R., "Solution of Plane Cascade Flow Using Improved Surface Singularity Methods, " Journal of Engineering for Power, Vol. 104, No. 3, JuTy 1982, pp. 668-674.

17. MCFarland, E.R., "A Rapid Blade-to-Blade Solution for Use in Turbomachinery Design," Journal of Engineering for Gas Turbines and Power, Vol. 106, No. 2, Apr. 1984, pp. 376-382.
18. Glawe, G.E., Krause, L.N. and Dudzinski, T.J., "A Small Combination Sensing Probe for Measurement of Temperature, Pressure, and Flow Direction," NASA TN-D-4816, 1963.

19. Lieblein, S. and Roudebush, W.H., "Theoretical Loss Relations for Low-Speed Two-DimensionalCascade Flow," NACA TN-3662, 1956.

20. Wattendorf, F.L., "Factors Influencing the Energy Ratio of Return Flow Wind Tunnels," Fifth International Congress for Applied Mechanics, J.P. Hartog and H. Peters, eds., Wiley, New York, 1939, pp. 526-530.

21. Eckert, W.T., Wettlaufer, B.M. and Mort, K.W., "The Aerodynamic Performance of Several Flow. Control Devices for Internal Flow Systems," NASA TP-1972, 1982. 

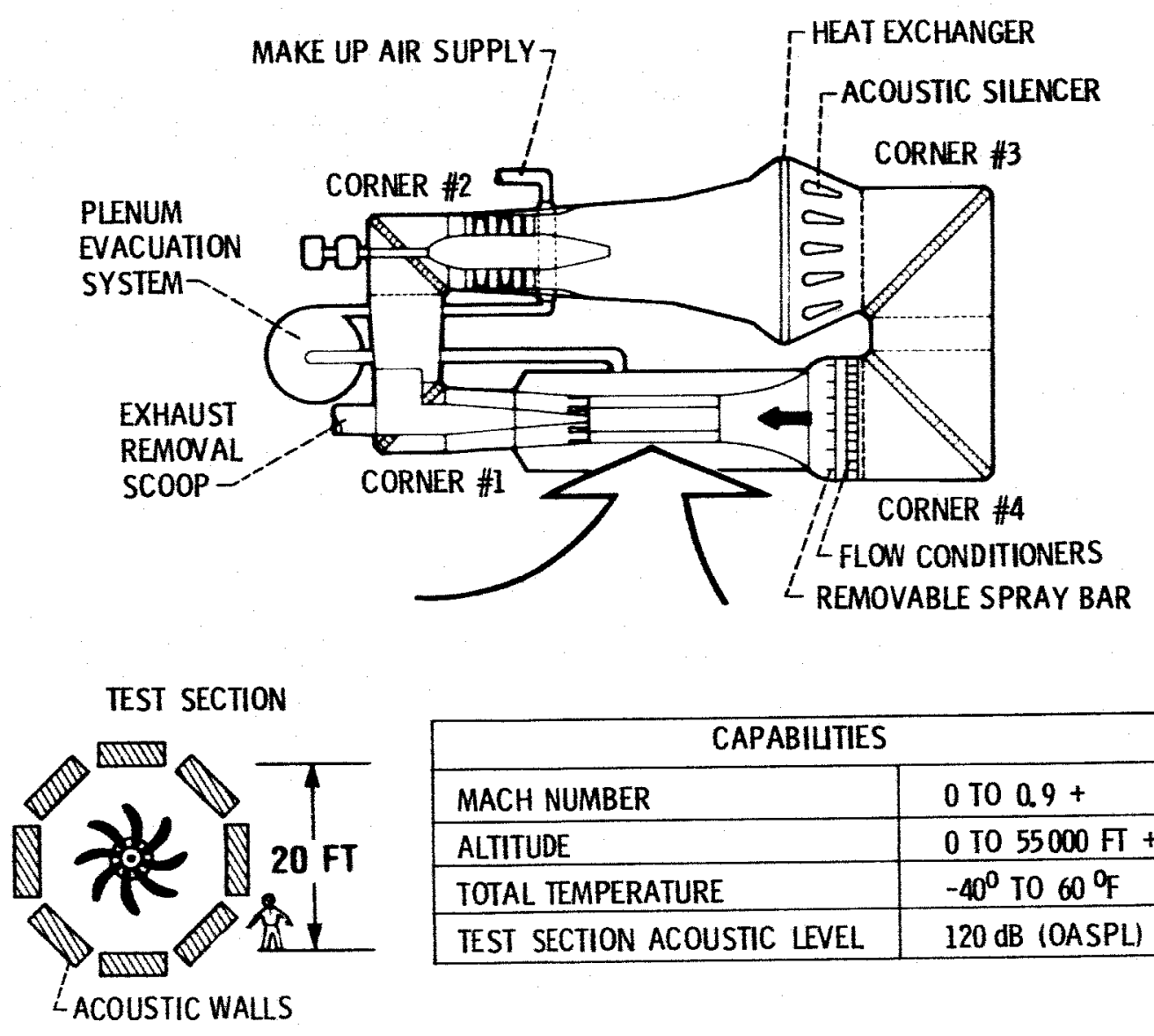

\begin{tabular}{|l|l|}
\hline \multicolumn{2}{|c|}{ CAPABIUTIES } \\
\hline MACH NUMBER & 0 TO $0.9+$ \\
\hline ALTITUDE & 0 TO $55000 \mathrm{FT}+$ \\
\hline TOTAL TEMPERATURE & $-40^{\circ} \mathrm{TO} 60^{\circ} \mathrm{F}$ \\
\hline TEST SECTION ACOUSTIC LEVEL & $120 \mathrm{~dB}$ (OASPL) \\
\hline
\end{tabular}

ACOUSTIC WALLS

Figure 1. - Capabilities of modified and rehabilitated AWT. 

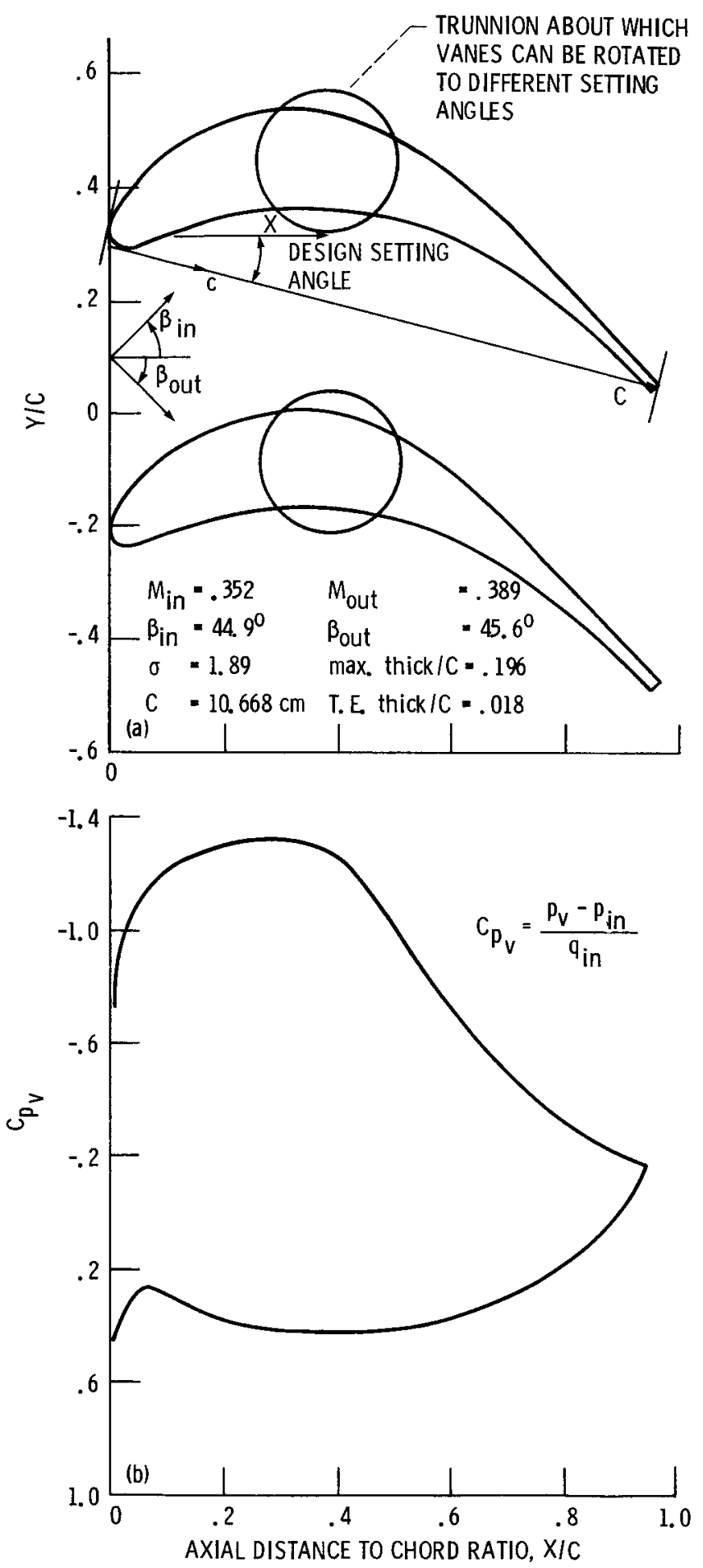

Figure 2. - Vane A design cross-section and surface pressure distribution (for vane coordinates see ref. 4). 

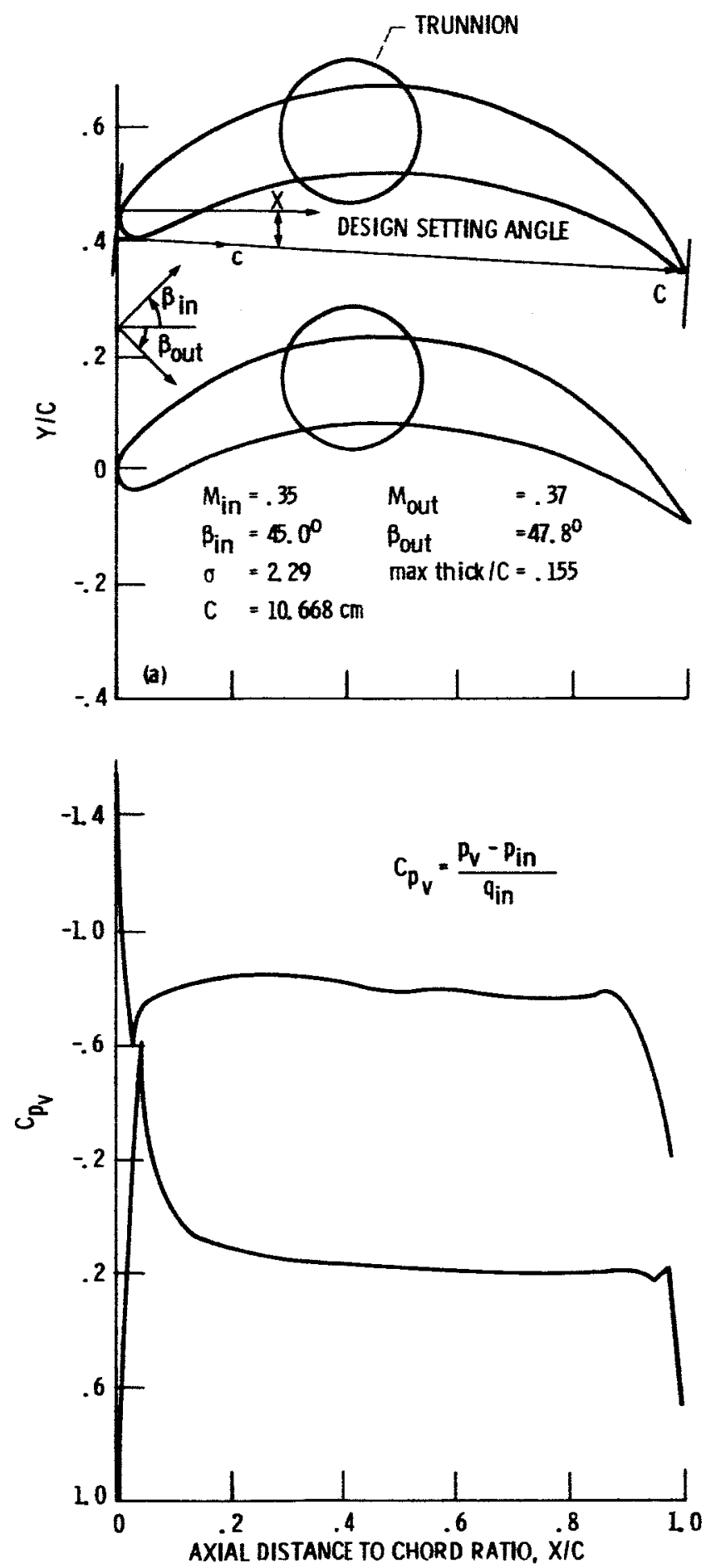

Figure 3. - Vane $B$ design cross-section and surface pressure distribution (for vane coordinates see ref. 4). 


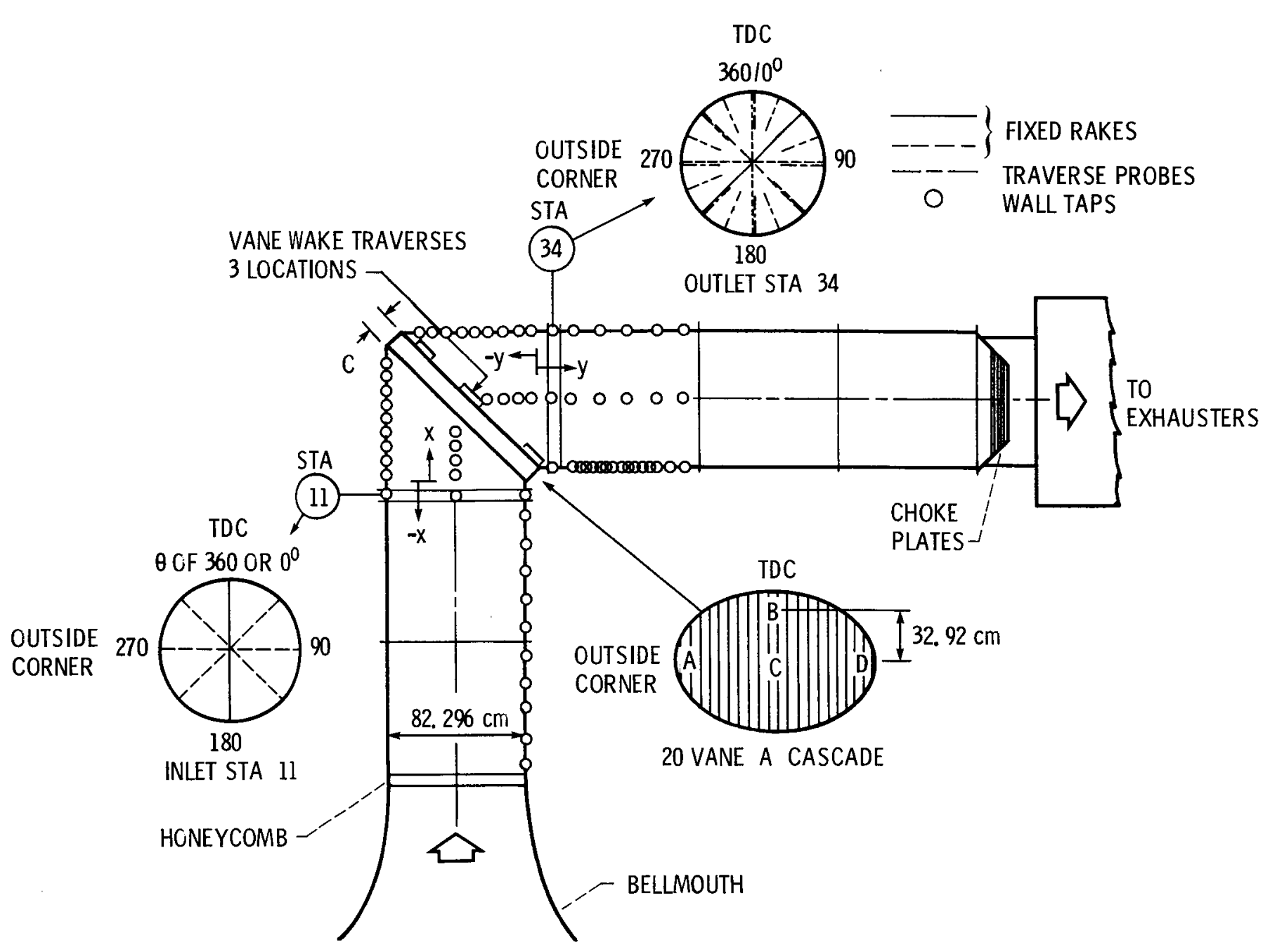

(a) Top and cross-sectional (looking downstream.) views.

\begin{tabular}{|c|c|c|c|c|c|}
\hline $\mathrm{x}, \mathrm{cm}$ & $\theta$, deg & $\mathrm{y}, \mathrm{cm}$ & $\theta$, deg & $\mathrm{y}, \mathrm{cm}$ & $\theta$, deg \\
\hline $\begin{array}{r}-167.92 \\
-151.46 \\
-135.00 \\
-118.54 \\
-102.08 \\
-85.62 \\
-69.16 \\
-52.71 \\
-36.25 \\
-19.79 \\
-\quad 7.75 \\
4.29 \\
12.52 \\
20.75 \\
28.98 \\
37.21 \\
45.44 \\
53.67 \\
61.90 \\
70.13\end{array}$ & $\mid$ & $\begin{array}{r}-70.13 \\
-61.90 \\
-53.67 \\
-45.44 \\
-37.21 \\
-28.98 \\
-20.75 \\
-12.52 \\
-4.29 \\
7.75\end{array}$ & $\mid$ & $\begin{array}{r}19.79 \\
23.90 \\
28.02 \\
32.13 \\
36.25 \\
40.36 \\
44.48 \\
48.59 \\
52.70 \\
56.82 \\
60.93 \\
65.05 \\
69.16 \\
77.39 \\
85.62\end{array}$ & $\begin{array}{c}0,270,180 \\
0,270,180 \\
0,270,180 \\
0,270,180\end{array}$ \\
\hline
\end{tabular}

(b) Location of wall static pressure taps.

Figure 4. - Scheniatic of test facility for 0.1-scale model tests of corner 1 with locations of instrumentation. 


\section{ORIGINAL PAGE IS \\ OF. POOR QUALITY}

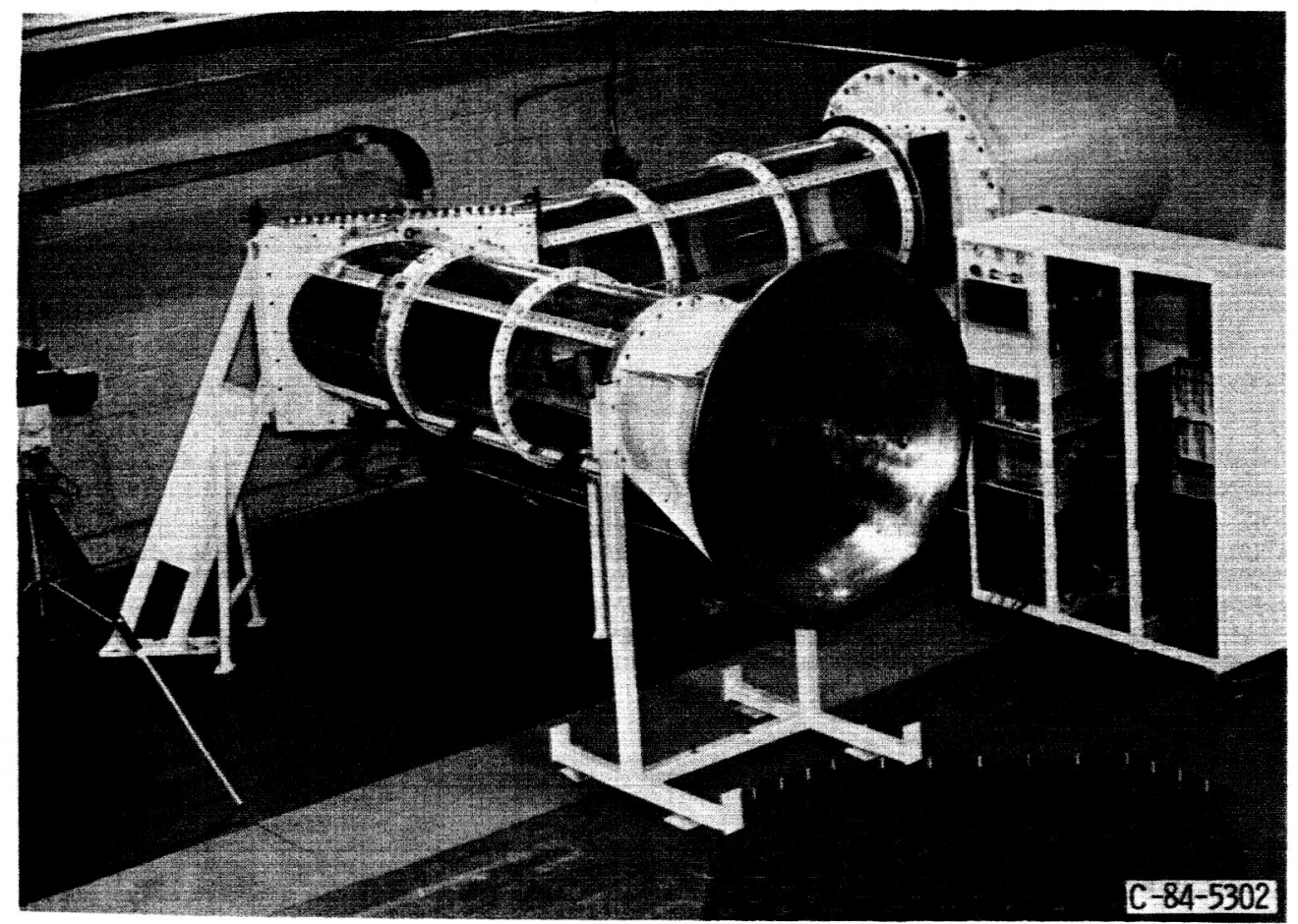

Figure 5. - Overall view of corner 1, 0.1-scale test facility.

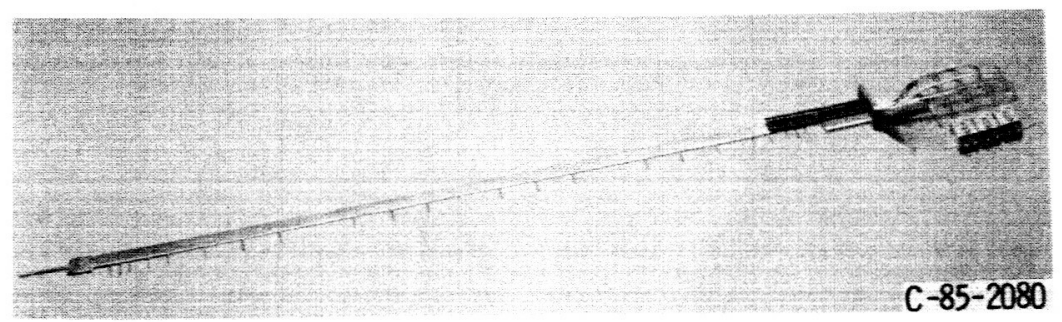

(a) Diametrical rake for total pressure and temperature.

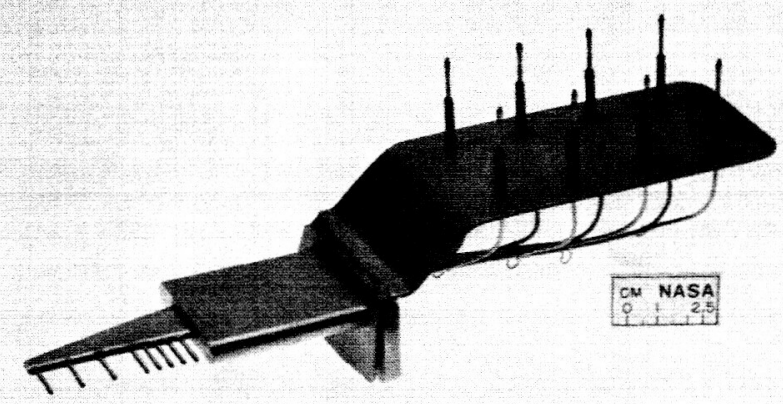

C-85-2081

(b) Boundary layer rake for total pressure.

Figure 6. - Instrumentation for 0.1 scale model tests of corner 1. 


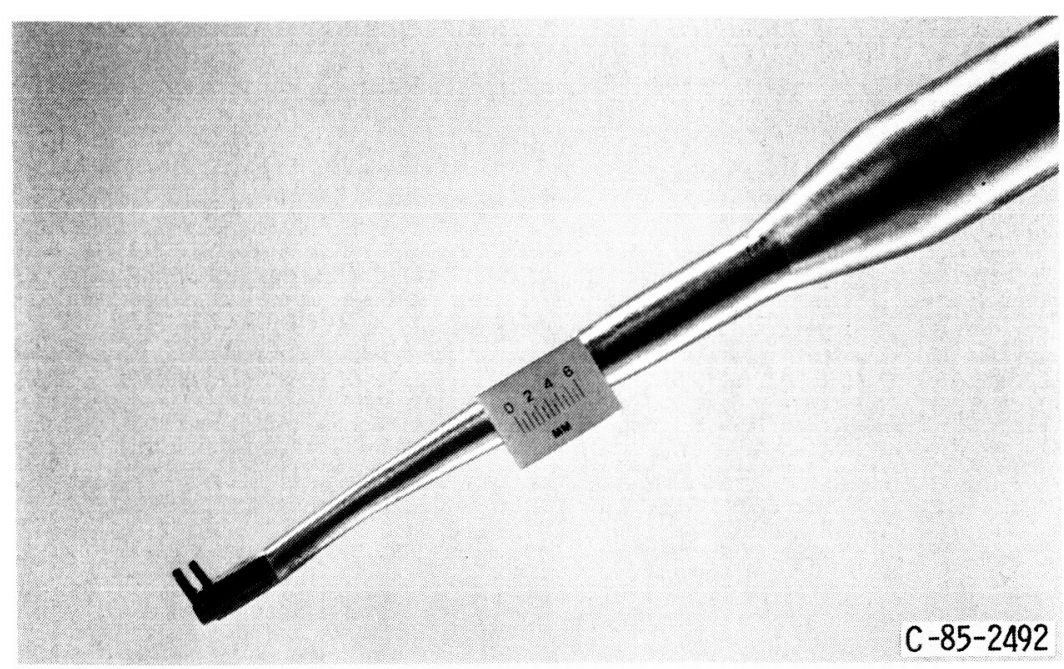

(c) Combination total pressure, total temperature, and tlow angle probe.

Figure 6. - Concluded。

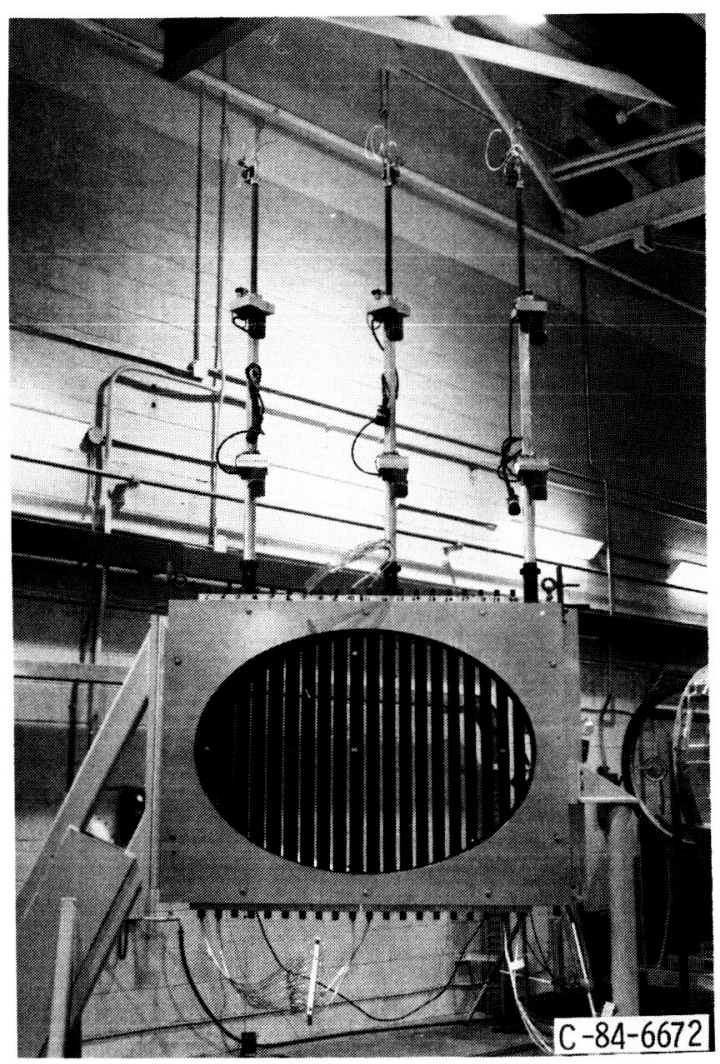

Figure 7。 - Front view of corner A vane pack with three wake survey probes mounted but withdrawn from airstream.

12 


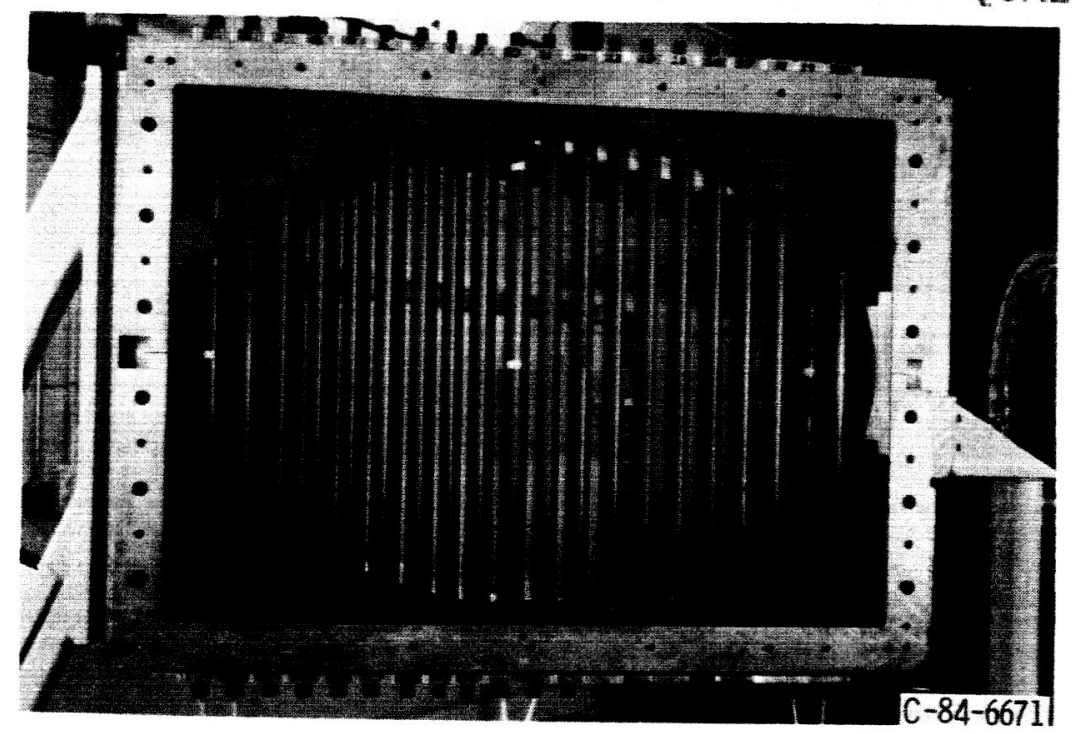

Figure 8. - Front view of corner A vane pack showing soft end walls.

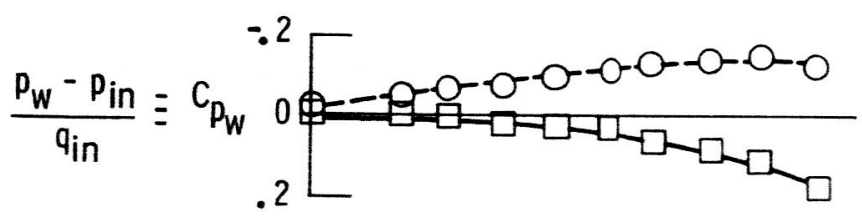

(a) Along corner inlet section.
SETTING

ANGLE,

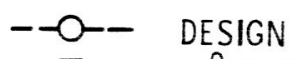

$\longrightarrow-5^{\circ}$ RESET

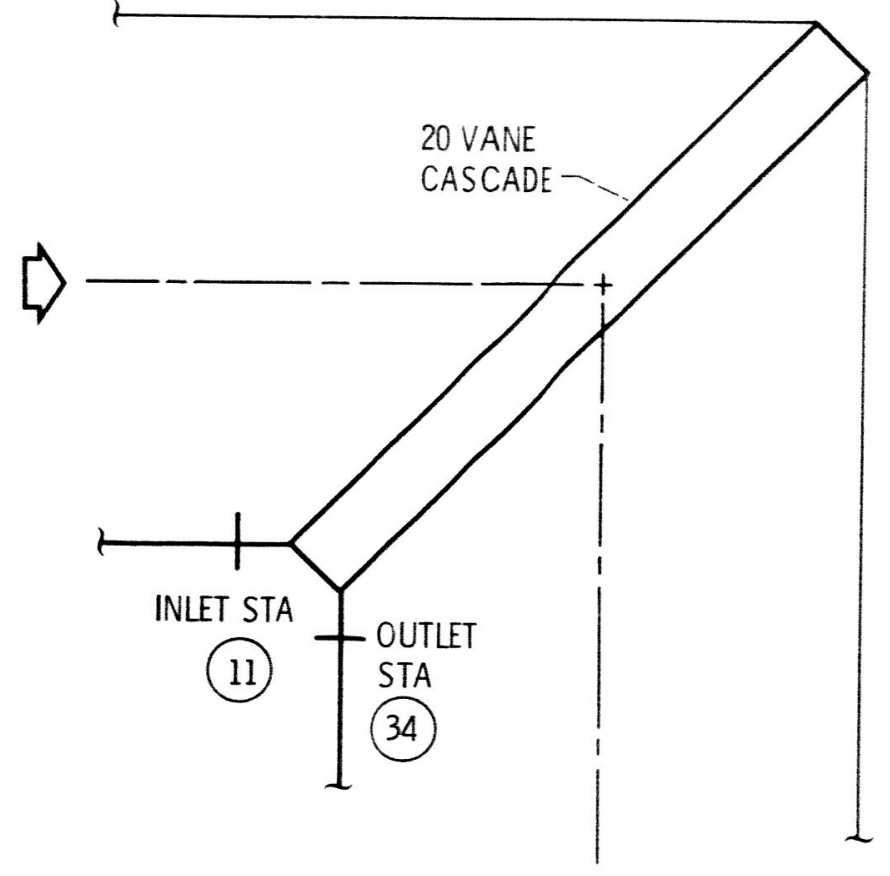

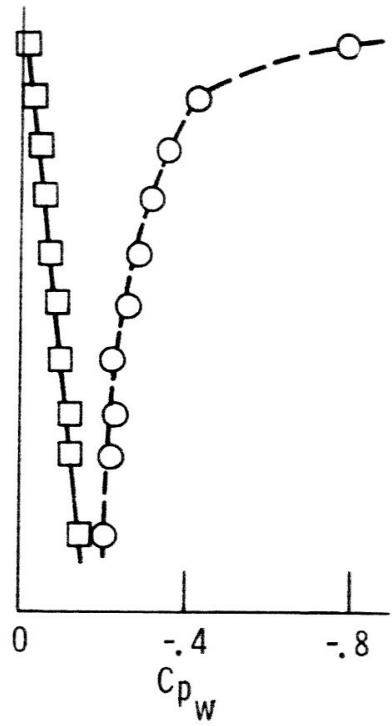

(b) Along corner outlet section.

Figure 9. - Static pressure distribution along outside corner walls at $\theta$ of $270^{\circ}$ for two van setting angles at design inlet Mach number of 0.35 . 


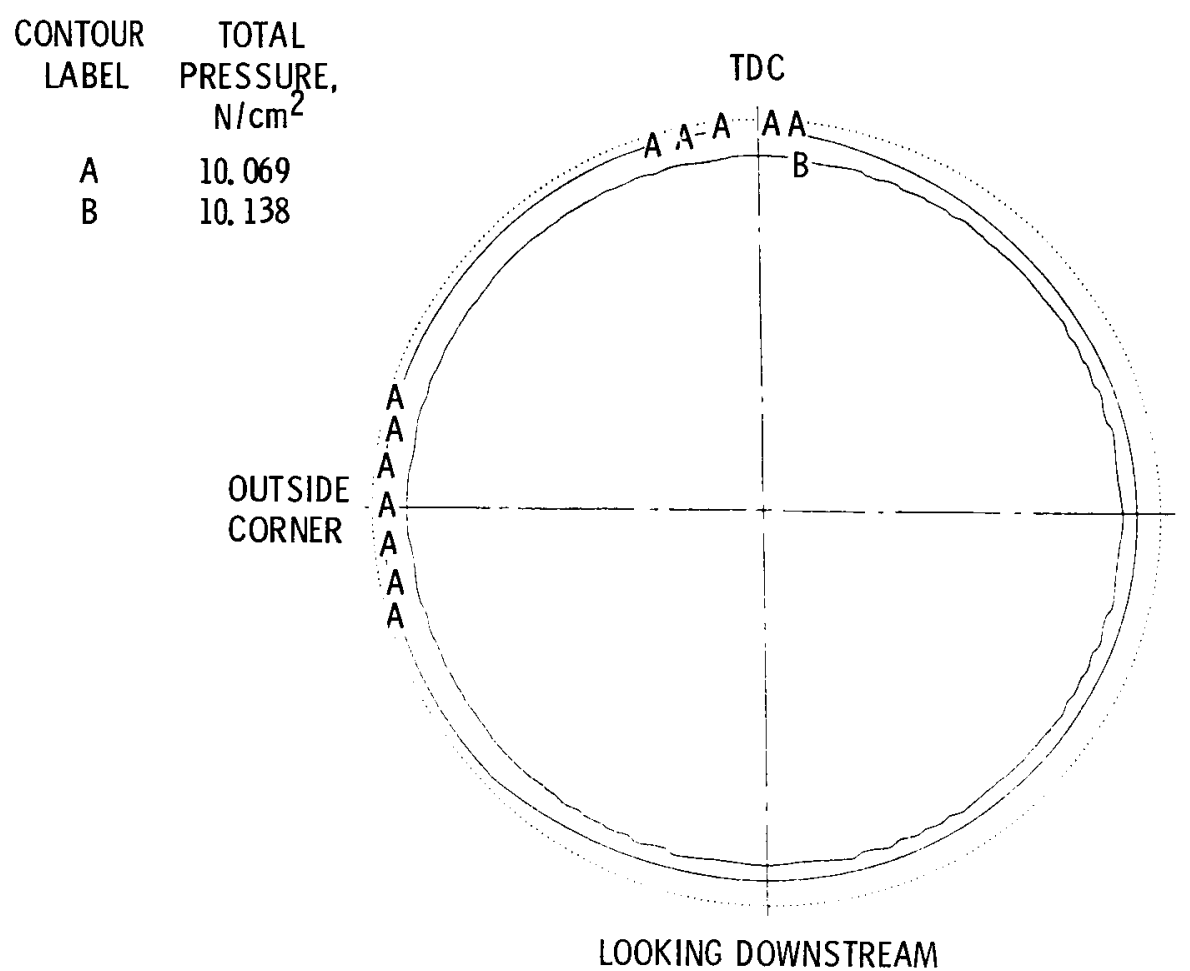

Figure 10. - Contour plot of inlet rake total pressures at station 11 and at design inlet Mach number of 0.35 . 


\section{ORIGINA $F:=13$ \\ OF POOR QUALITY}

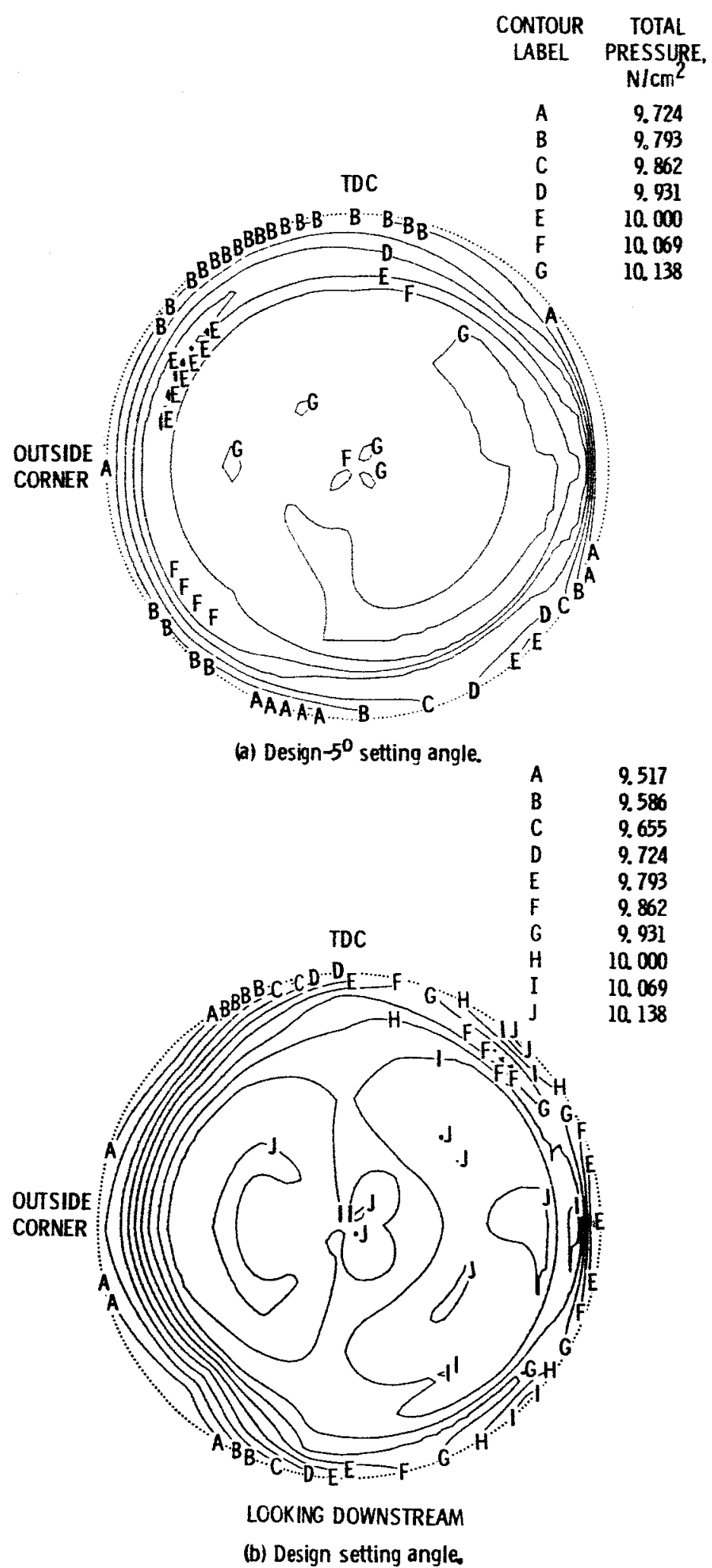

Figure 11 - Contour plots of outlet rake total pressures at station 34 and at design inlet Mach number of $Q 35$. 


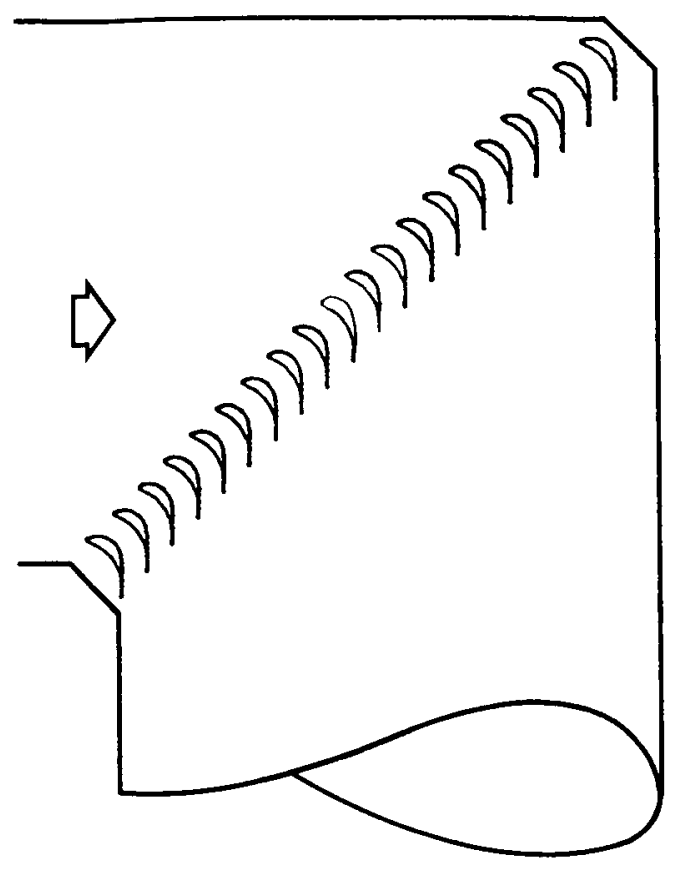

(a) Actual tested.

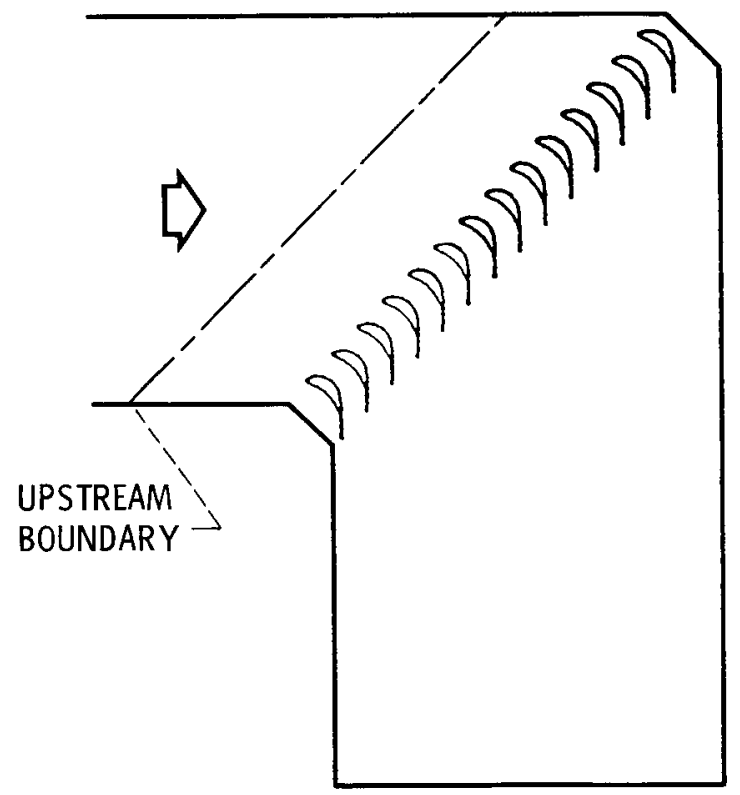

(b) $2 \mathrm{D}$ simulation for analysis, includes different vane setting angles.

Figure 12. - Corner configurations studied. 


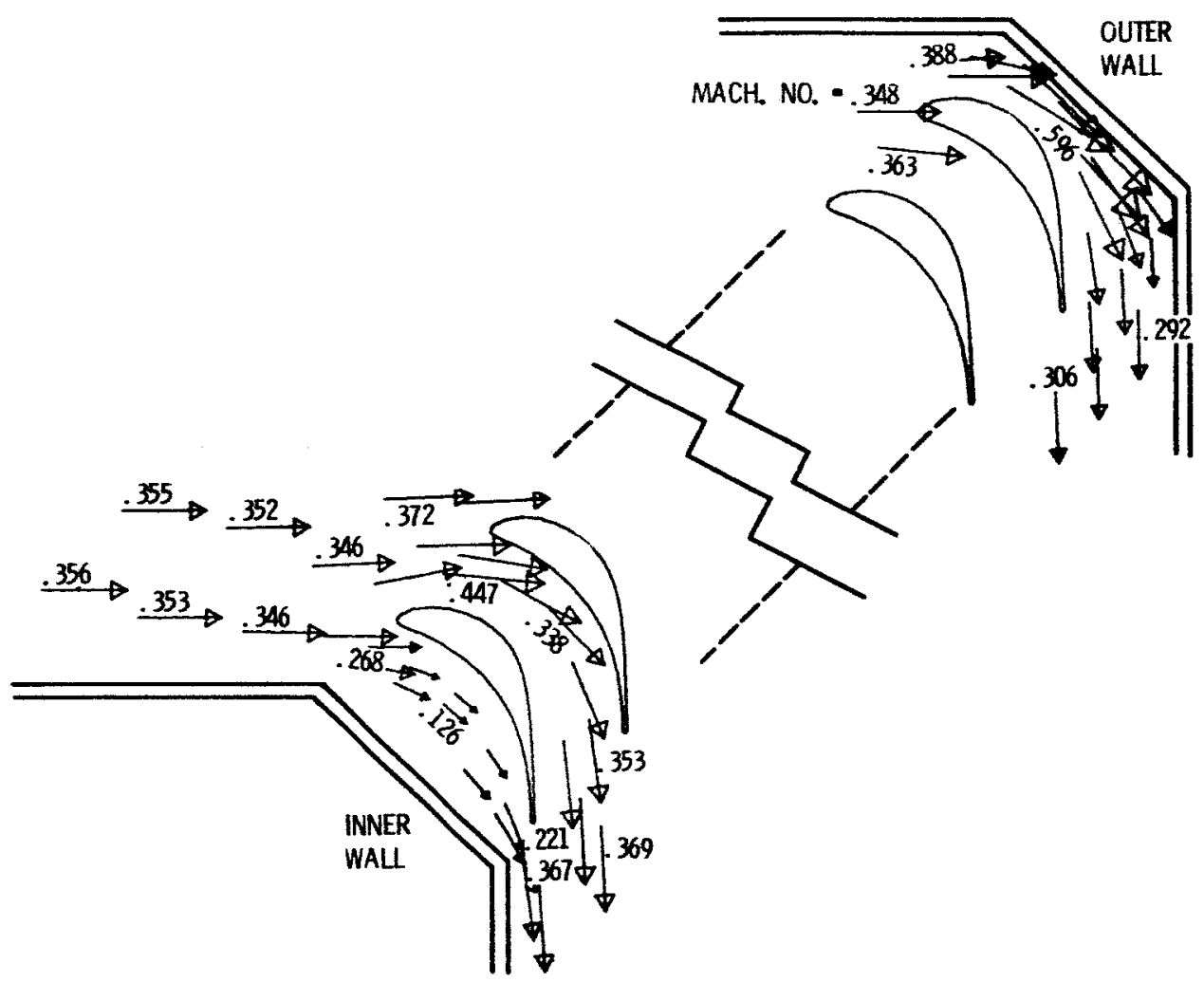

(a) Design $-5^{\circ}$ setting angle.

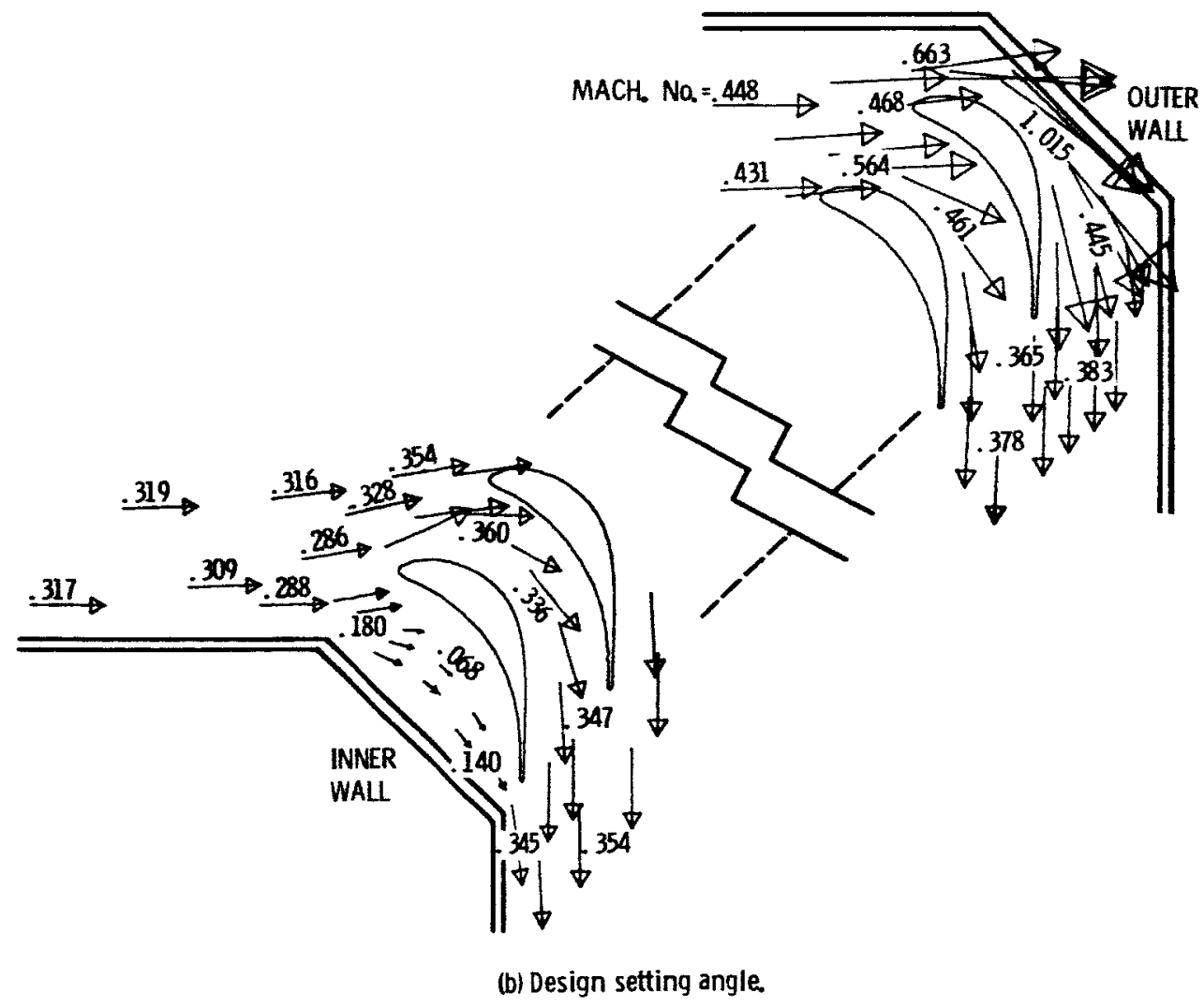

Figure 13. - Flow vectors near inner and outer walls of corner for two vane setting angles at desiqn intet Mach number of 0.35 . 


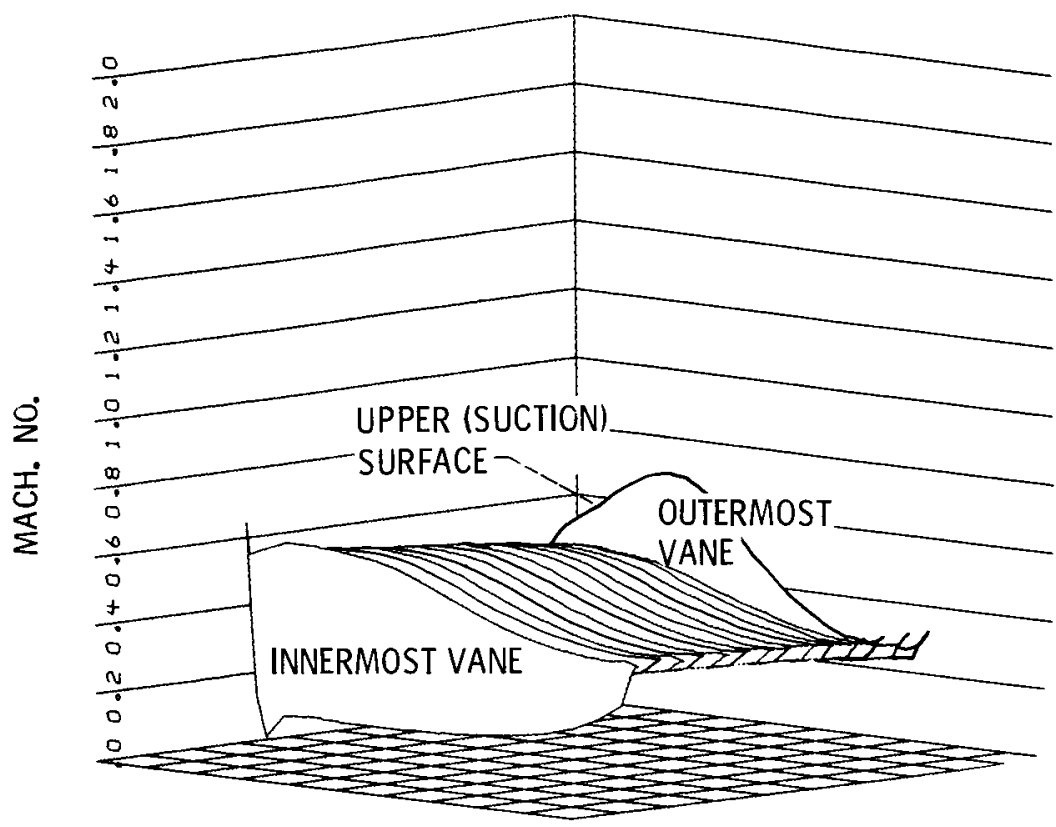

(a) Design $-5^{\circ}$.

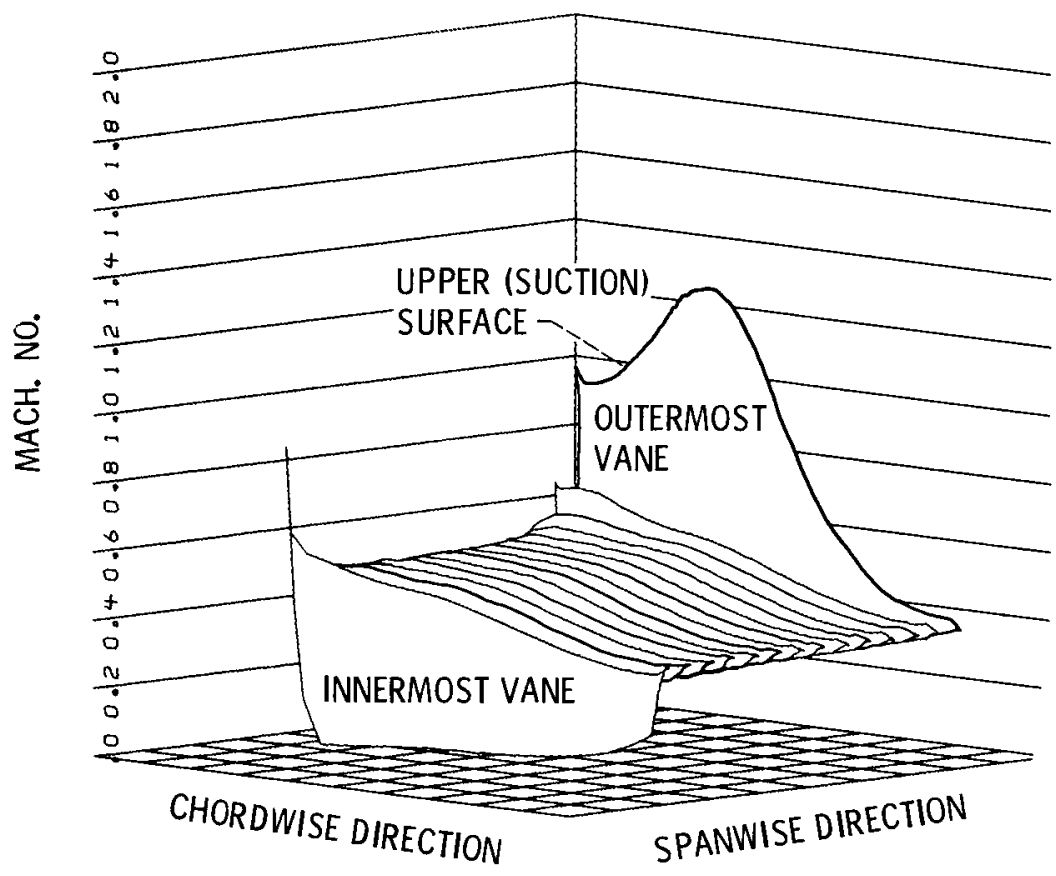

(b) Design.

Figure 14. - Carpet plots of vane surface Mach number for two vane setting angles at design inlet Mach number of 0.35 . 
ORIGINAL PREE

OF POOR QUJASITY
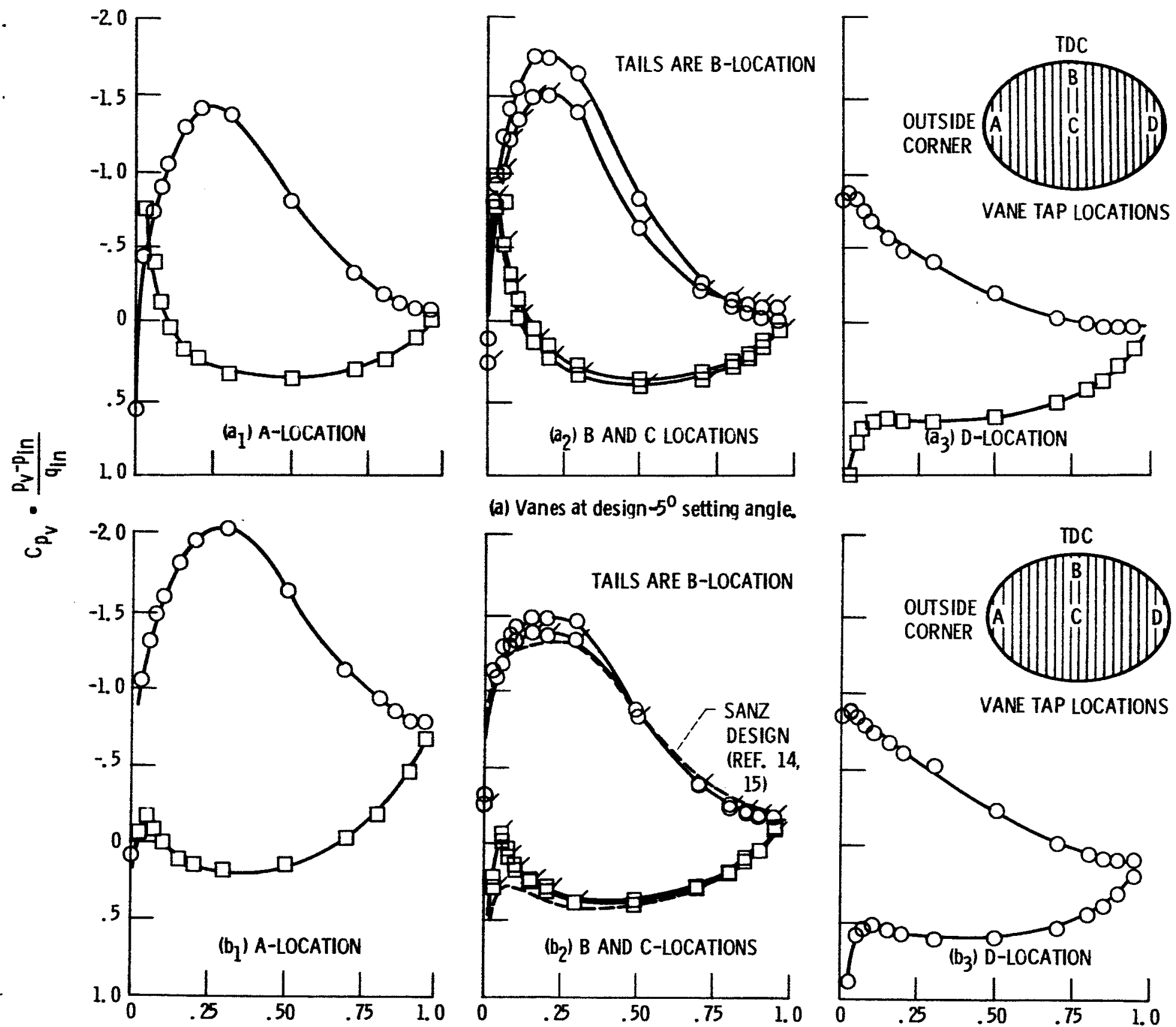

(a) Vanes at design $-5^{0}$ setting angle.
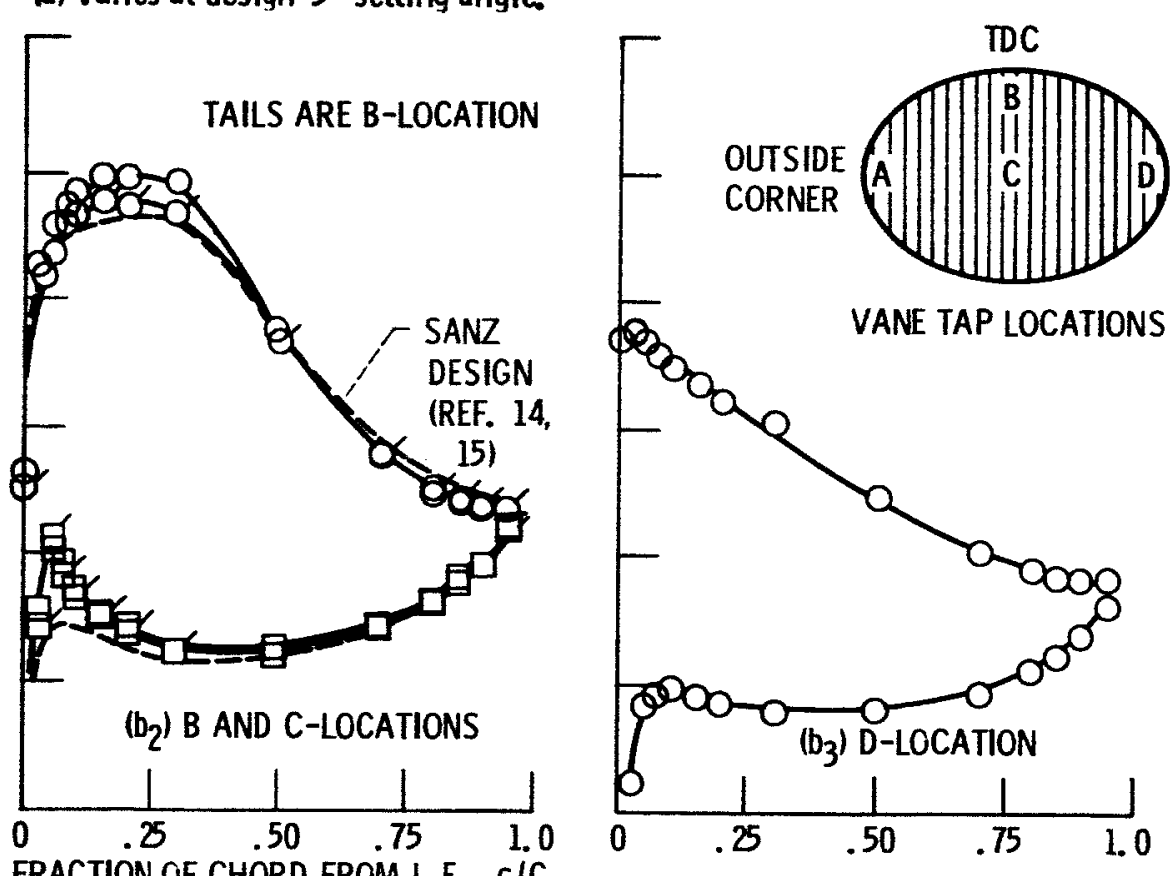

FRACTION OF CHORD FROM LE, CIC

(b) Vanes at design setting angle.

Figure 15. - Vane A surface pressure distributions at four locations at design inlet Mach number of 0.35 . 

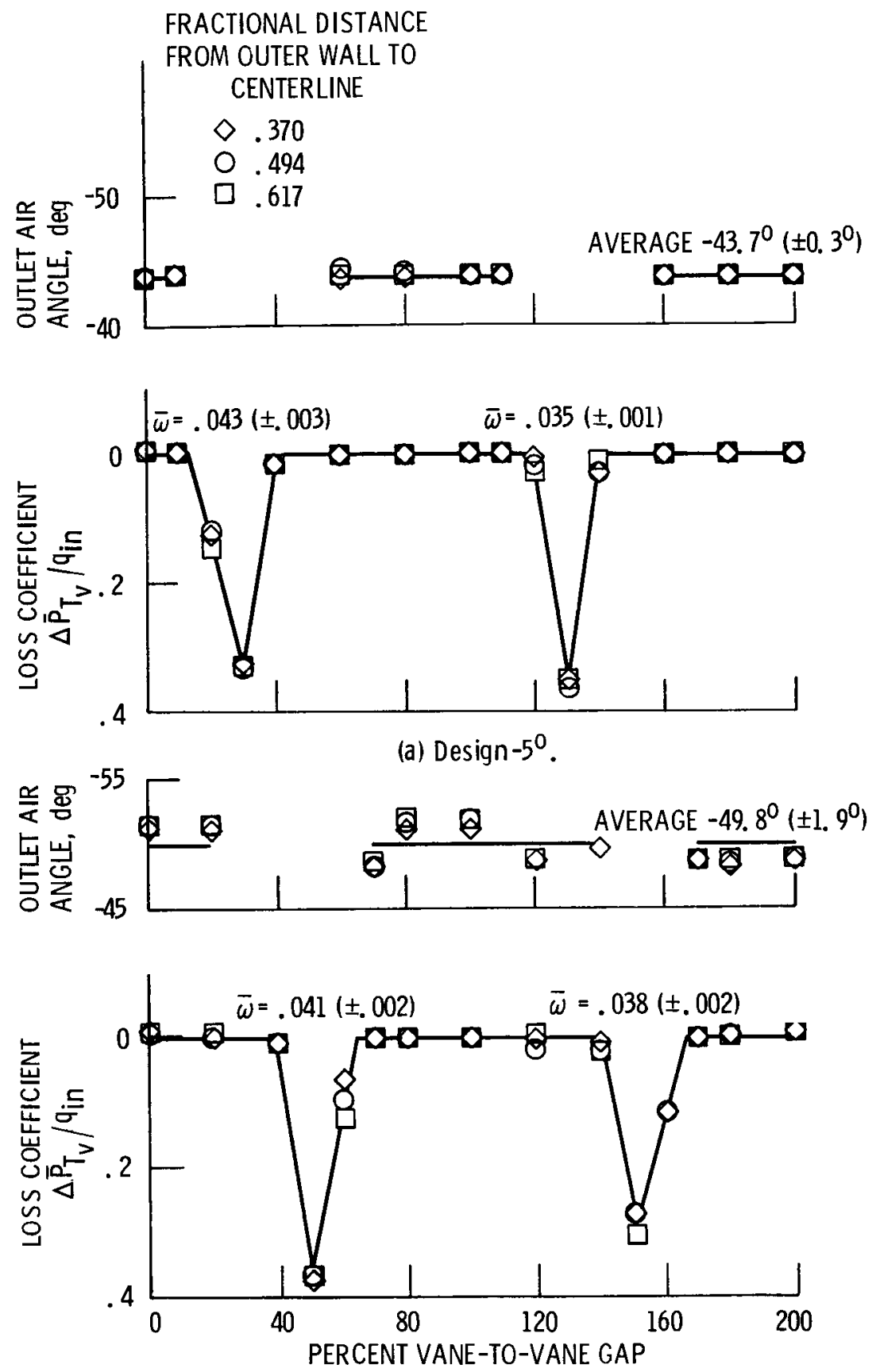

(b) Design.

Figure 16. - Total pressure and outlet air angle distribution 0.5 -chord downstream of central apir of vanes at two pack setting angles. Inlet Mach number of 0.35 . 


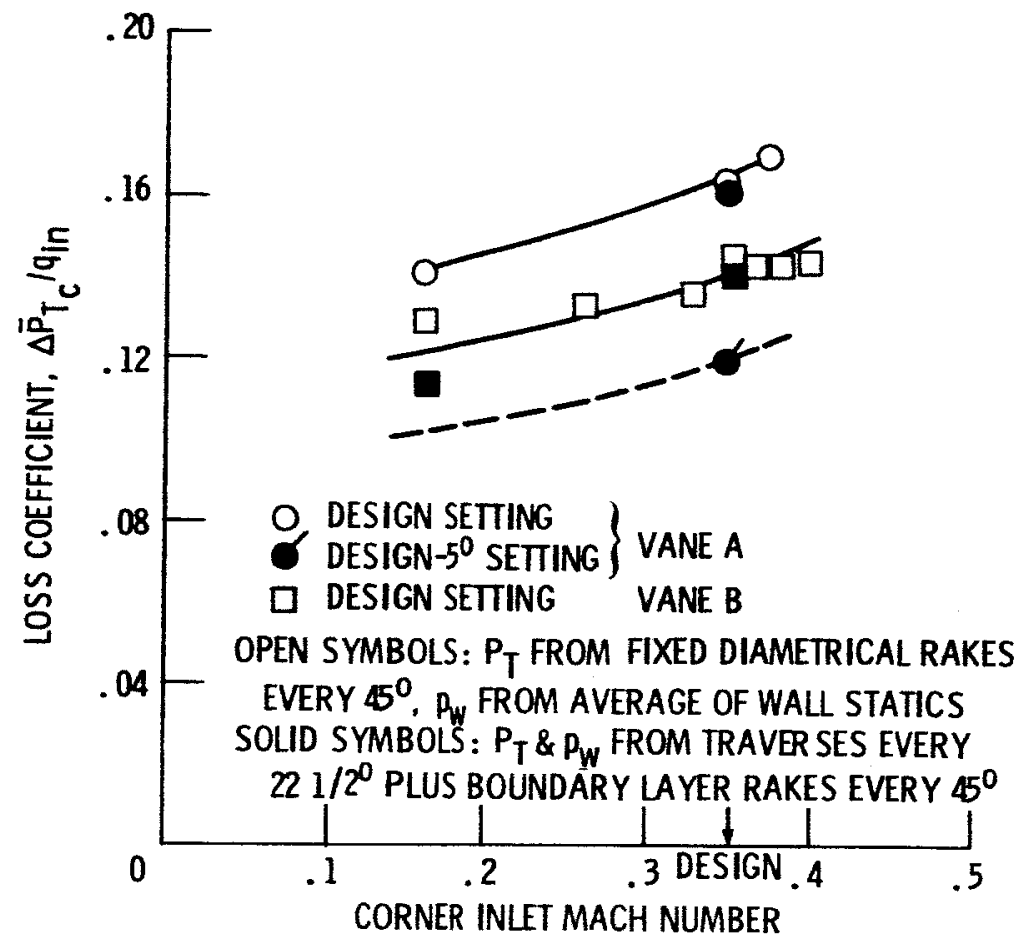

Figure 17. - Corner 1 loss coefficients as a function of inlet Mach number and vane desiạn. 


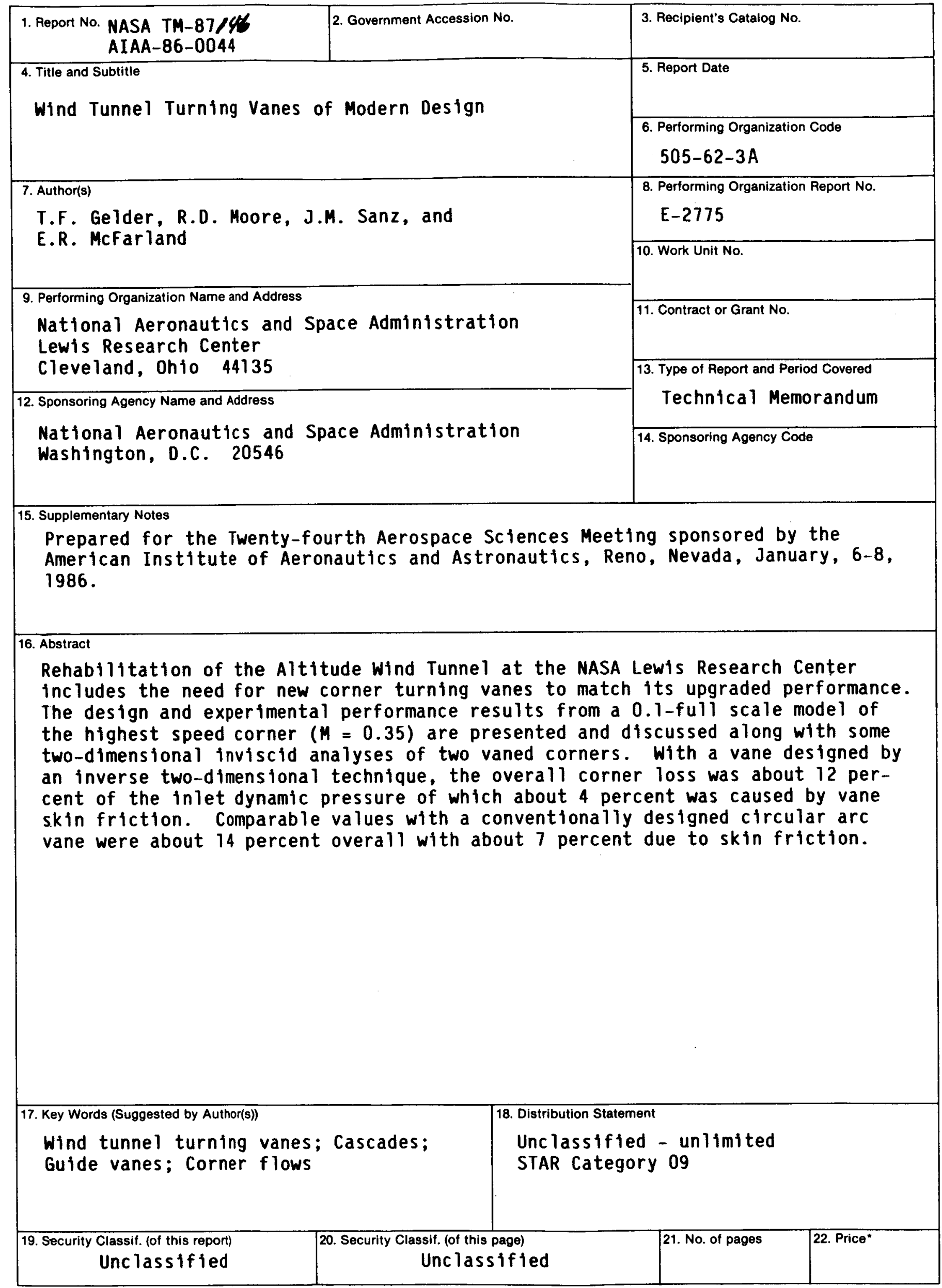

"For sale by the National Technical Information Service, Springfield, Virginia 22161 